\title{
Observational assessment of the role of nocturnal residual-layer chemistry in determining daytime surface particulate nitrate concentrations
}

\author{
Gouri Prabhakar $^{1}$, Caroline L. Parworth ${ }^{2}$, Xiaolu Zhang ${ }^{1}$, Hwajin Kim ${ }^{2, a}$, Dominique E. Young ${ }^{2, b}$, \\ Andreas J. Beyersdorf ${ }^{3, c}$, Luke D. Ziemba ${ }^{3}$, John B. Nowak ${ }^{3}$, Timothy H. Bertram ${ }^{4}$, Ian C. Faloona ${ }^{5}$, Qi Zhang ${ }^{2}$, and \\ Christopher D. Cappa ${ }^{1}$ \\ ${ }^{1}$ Department of Civil and Environmental Engineering, University of California, Davis, Davis, CA, USA \\ ${ }^{2}$ Department of Environmental Toxicology, University of California, Davis, Davis, CA, USA \\ ${ }^{3}$ NASA Langley Research Center, Hampton, Virginia, USA \\ ${ }^{4}$ Department of Chemistry, University of Wisconsin, Madison, WI, USA \\ ${ }^{5}$ Department of Land, Air and Water Resources, University of California, Davis, Davis, CA, USA \\ ${ }^{a}$ now at: Center for Environment, Health and Welfare Research, Korea Institute of Science and Technology, \\ Seoul, South Korea \\ ${ }^{\mathrm{b}}$ now at: Air Quality Research Center, University of California, Davis, Davis, California, USA \\ ${ }^{c}$ now at: Department of Chemistry, California State University, San Bernardino, San Bernardino, CA, USA
}

Correspondence: Christopher D. Cappa (cdcappa@ucdavis.edu) and Gouri Prabhakar (gourip@ucdavis.edu)

Received: 9 June 2017 - Discussion started: 27 June 2017

Revised: 22 September 2017 - Accepted: 10 October 2017 - Published: 12 December 2017

\begin{abstract}
This study discusses an analysis of combined airborne and ground observations of particulate nitrate $\left(\mathrm{NO}_{3}^{-}(\mathrm{p})\right.$ ) concentrations made during the wintertime DISCOVER-AQ (Deriving Information on Surface Conditions from COlumn and VERtically resolved observations relevant to Air Quality) study at one of the most polluted cities in the United States - Fresno, CA - in the San Joaquin Valley (SJV) and focuses on developing an understanding of the various processes that impact surface nitrate concentrations during pollution events. The results provide an explicit case-study illustration of how nighttime chemistry can influence daytime surface-level $\mathrm{NO}_{3}^{-}(\mathrm{p})$ concentrations, complementing previous studies in the SJV. The observations exemplify the critical role that nocturnal chemical production of $\mathrm{NO}_{3}^{-}(\mathrm{p})$ aloft in the residual layer (RL) can play in determining daytime surface-level $\mathrm{NO}_{3}^{-}$(p) concentrations. Further, they indicate that nocturnal production of $\mathrm{NO}_{3}^{-}(\mathrm{p})$ in the RL, along with daytime photochemical production, can contribute substantially to the buildup and sustaining of severe pollution episodes. The exceptionally shallow nocturnal boundary layer (NBL) heights characteristic of wintertime pollution events in the SJV intensify the importance
\end{abstract}

of nocturnal production aloft in the residual layer to daytime surface concentrations. The observations also demonstrate that dynamics within the RL can influence the earlymorning vertical distribution of $\mathrm{NO}_{3}^{-}(\mathrm{p})$, despite low wintertime wind speeds. This overnight reshaping of the vertical distribution above the city plays an important role in determining the net impact of nocturnal chemical production on local and regional surface-level $\mathrm{NO}_{3}^{-}(\mathrm{p})$ concentrations. Entrainment of clean free-tropospheric (FT) air into the boundary layer in the afternoon is identified as an important process that reduces surface-level $\mathrm{NO}_{3}^{-}(\mathrm{p})$ and limits buildup during pollution episodes. The influence of dry deposition of $\mathrm{HNO}_{3}$ gas to the surface on daytime particulate nitrate concentrations is important but limited by an excess of ammonia in the region, which leads to only a small fraction of nitrate existing in the gas phase even during the warmer daytime. However, in the late afternoon, when diminishing solar heating leads to a rapid fall in the mixed boundary layer height (BLH), the impact of surface deposition is temporarily enhanced and can lead to a substantial decline in surface-level particulate nitrate concentrations; this enhanced deposition is quickly arrested by a decrease in surface temperature, which 
drops the gas-phase fraction to near zero. The overall importance of enhanced late-afternoon gas-phase loss to the multiday buildup of pollution events is limited by the very shallow nocturnal boundary layer. The case study here demonstrates that mixing down of $\mathrm{NO}_{3}^{-}(\mathrm{p})$ from the $\mathrm{RL}$ can contribute a majority of the surface-level $\mathrm{NO}_{3}^{-}(\mathrm{p})$ in the morning (here, $\sim 80 \%$ ), and a strong influence can persist into the afternoon even when photochemical production is maximum. The particular day-to-day contribution of aloft nocturnal $\mathrm{NO}_{3}^{-}(\mathrm{p})$ production to surface concentrations will depend on prevailing chemical and meteorological conditions. Although specific to the SJV, the observations and conceptual framework further developed here provide general insights into the evolution of pollution episodes in wintertime environments.

\section{Introduction}

Nocturnal processing of nitrogen oxides, $\mathrm{NO}_{x}(=\mathrm{NO}+$ $\mathrm{NO}_{2}$ ), can strongly influence daytime air quality (Dentener and Crutzen, 1993; Brown et al., 2006c). At night, once photochemical reactions shutdown, $\mathrm{NO}_{x}$ reacts with ozone $\left(\mathrm{O}_{3}\right)$ to form nitrate radical $\left(\mathrm{NO}_{3}\right)$ and dinitrogen pentoxide $\left(\mathrm{N}_{2} \mathrm{O}_{5}\right)$ (Reactions $\mathrm{R} 1$ through $\mathrm{R} 3 \mathrm{a}$ ). $\mathrm{N}_{2} \mathrm{O}_{5}$ can react heterogeneously with airborne particles to form either nitric acid $\left(\mathrm{HNO}_{3}\right)$ (Reaction $\mathrm{R} 4 \mathrm{a}$ ) or, in the presence of particulate chloride, nitryl chloride $\left(\mathrm{ClNO}_{2}\right)$ (Reaction $\mathrm{R} 4 \mathrm{~b}$, where $Y_{\mathrm{ClNO}_{2}}$ represents the molar yield of $\mathrm{ClNO}_{2}$ with respect to the $\mathrm{N}_{2} \mathrm{O}_{5}$ reacted). In the presence of basic species like ammonia $\left(\mathrm{NH}_{3}\right), \mathrm{HNO}_{3}$ can be neutralized to form particulate nitrate $\left(\mathrm{NO}_{3}^{-}(\mathrm{p})\right) . \mathrm{NO}_{3}$ radicals can alternatively react with volatile organic compounds (VOCs), which suppresses $\mathrm{HNO}_{3}$ formation (Reaction R3b). Much research has focused on the influence of nocturnal $\mathrm{NO}_{x}$ processing on the regional budgets of $\mathrm{NO}_{x}$ and $\mathrm{O}_{3}$ and on the oxidative capacity of the atmosphere during subsequent mornings (e.g., Brown et al., 2006b; Thornton et al., 2010; Wild et al., 2016). The corresponding impact of nighttime production of $\mathrm{NO}_{3}^{-}(\mathrm{g}+\mathrm{p})$, a key nocturnal sink for $\mathrm{NO}_{x}$, on local and regional air quality can be considerable (Lowe et al., 2015; Pusede et al., 2016) but is less often considered in detail.

$\mathrm{NO}+\mathrm{O}_{3} \rightarrow \mathrm{NO}_{2}+\mathrm{O}_{2}$

$\mathrm{NO}_{2}+\mathrm{O}_{3} \rightarrow \mathrm{NO}_{3}+\mathrm{O}_{2}$

$\mathrm{NO}_{2}+\mathrm{NO}_{3} \leftrightarrow \mathrm{N}_{2} \mathrm{O}_{5}$

$\mathrm{NO}_{3}+\mathrm{VOC} \rightarrow$ products

$\mathrm{N}_{2} \mathrm{O}_{5}+\mathrm{H}_{2} \mathrm{O}$ (het) $\rightarrow 2 \mathrm{HNO}_{3}$

$\mathrm{N}_{2} \mathrm{O}_{5}+\mathrm{Cl}^{-}$(het) $\rightarrow Y_{\mathrm{ClNO}_{2}}+\left(2-Y_{\mathrm{ClNO}_{2}}\right) \mathrm{NO}_{3}^{-}$

The importance of nocturnal $\mathrm{NO}_{x}$ chemistry to $\mathrm{NO}_{3}^{-}$(p) production can be especially important in the winter. Relative to summer, nights in winter are longer, colder and more humid, and biogenic VOC emissions tend to be smaller. This allows for a larger fraction of $\mathrm{NO}_{2}$ to be oxidized to $\mathrm{HNO}_{3}$ via the $\mathrm{N}_{2} \mathrm{O}_{5}$ hydrolysis pathway (Cabañas et al., 2001; Wagner et al., 2013), and colder temperatures favor partitioning of nitrate to the particle phase (Stelson and Seinfeld, 1982). In winter, nighttime $\mathrm{HNO}_{3}$ production can more efficiently compete with daytime photochemically driven production due to the low photolysis rates and hydroxyl radical concentrations (Wagner et al., 2013; Pusede et al., 2016). Multiday pollution events (i.e., periods with elevated particulate matter, PM, concentrations) can occur when meteorological conditions inhibit dispersion, as is the case with the persistent cold air pool formation often found in valley regions (Whiteman et al., 2014; Baasandorj et al., 2017). During the daytime, sunlight-driven convection leads to an evolution of the near-surface temperature profile and causes the atmosphere to be reasonably well mixed up to some height (typically less than $1 \mathrm{~km}$; cf. Fig. S1 in the Supplement). Radiative cooling in the late afternoon leads this mixed layer (ML) to decouple and separate into a shallow, near-surface-level nocturnal boundary layer (NBL) and a residual layer (RL) aloft, the behavior of which can be further modified by valley flows.

Nocturnal conversion of $\mathrm{NO}_{x}$ to $\mathrm{NO}_{3}^{-}$(p) can occur either in the NBL or the RL. Surface NO emissions can substantially limit direct production of $\mathrm{NO}_{3}^{-}$(p) in the NBL by titrating $\mathrm{O}_{3}$, depending on the initial conditions. Nocturnal surface $\mathrm{NO}$ emissions do not directly influence the decoupled $\mathrm{RL}$, with chemical production of $\mathrm{NO}_{3}^{-}(\mathrm{p})$ dependent on the $\mathrm{NO}_{x}, \mathrm{O}_{3}$ and particulate matter in the mixed layer at the time of decoupling. Box and 3-D models have been previously used to assess the contribution of nocturnal processes in the RL to the daytime surface concentrations of particulate matter, especially $\mathrm{NO}_{3}^{-}$(p) (Riemer et al., 2003; Curci et al., 2015). Yet, computational models often have difficulty in accurately predicting surface $\mathrm{NO}_{3}^{-}$(p) in many regions, particularly in the winter season, despite good estimations of $\mathrm{NO}_{x}$ emissions (Walker et al., 2012; Terrenoire et al., 2015), although this is not always the case (e.g., Schiferl et al., 2014). Here, airborne and ground measurements made over Fresno, CA, in the San Joaquin Valley (SJV) during the wintertime 2013 DISCOVER-AQ (Deriving Information on Surface Conditions from COlumn and VERtically resolved observations relevant to Air Quality; Appendix A) (Crawford and Pickering, 2014) study are used to further develop our understanding of the role that different factors play in determining surface-level $\mathrm{NO}_{3}^{-}(\mathrm{p})$ concentrations.

Winters in Fresno are characterized by frequent multiday pollution episodes (Chow et al., 1999; Watson and Chow, 2002), when $\mathrm{PM}_{2.5}$ (PM with aerodynamic diameter $<2.5 \mu \mathrm{m}$ ) mass concentrations exceed the $24 \mathrm{~h}$ National Ambient Air Quality Standard (NAAQS) of $35 \mu \mathrm{g} \mathrm{m}^{-3}$ (Fig. 1). Fresno is one of the largest cities in the San Joaquin Valley, which is largely an agricultural area and suffers from some of the worst air pollution in the United States (American Lung Association, 2014). Shallow daytime mixed layer heights and low wind speeds in winter lead to the accumulation of pollutants across the valley (San Joaquin Valley Air 


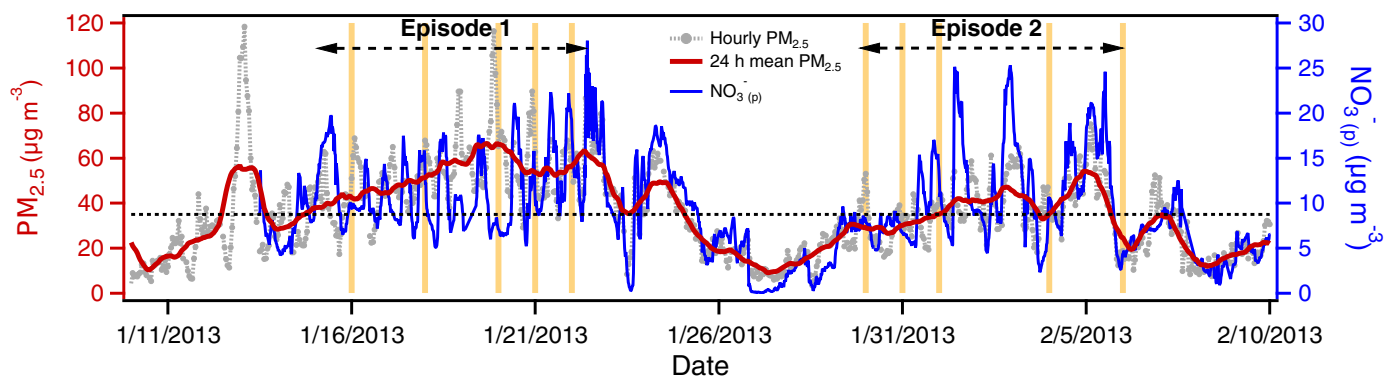

Figure 1. Time series of surface $\mathrm{PM}_{2.5}$ concentration $\left(\mu \mathrm{g} \mathrm{m}^{-3}\right)$ measured in Fresno during the DISCOVER-AQ campaign for $1 \mathrm{~h}$ averages (light red dotted line) and for a running average (red line, smoothed over $24 \mathrm{~h}$ ), along with the $1 \mathrm{~h}$ average $\mathrm{NO}_{3}^{-}$(p) concentration (blue line). The vertical orange lines indicate the days on which airborne measurements were made. The horizontal dashed black line indicates the NAAQS $24 \mathrm{~h}$ standard of $35 \mu \mathrm{g} \mathrm{m}^{-3}$ for $\mathrm{PM}_{2.5}$.

Pollution Control District, 2003). Previous observations in the SJV region have found a buildup of $\mathrm{NH}_{4} \mathrm{NO}_{3}$ during pollution episodes (e.g., Chow et al., 2008). Approximately 30$80 \%$ of the wintertime $\mathrm{PM}_{2.5}$ mass in this region is ammonium nitrate $\left(\mathrm{NH}_{4} \mathrm{NO}_{3}\right)$, with a strong diurnal variability, and most other $\mathrm{PM}_{2.5}$ is organic matter (Chow et al., 2006; Ge et al., 2012; Young et al., 2016; Parworth et al., 2017). During DISCOVER-AQ specifically, $\mathrm{NO}_{3}^{-}$(p) was found to represent $28 \%$ of non-refractory $\mathrm{PM}_{1.0}\left(\mathrm{NR}-\mathrm{PM}_{1} ; \mathrm{PM}_{1.0}, \mathrm{PM}\right.$ with aerodynamic diameter $<1 \mu \mathrm{m}$ ) mass on average (Young et al., 2016).

An important role for nocturnal $\mathrm{NO}_{3}^{-}$(p) production in this region has been previously identified based on observations of long-term trends, the spatial and diurnal variability in $\mathrm{NO}_{3}^{-}(\mathrm{p})$, and the chemical environment in and around Fresno. For example, Watson and Chow (2002) reported a sharp, early-morning ( 09:00 LT, local time) increase in surface $\mathrm{NO}_{3}^{-}$(p) concentrations on many days of a severe pollution episode in 2000 and suggested that this behavior was consistent with mixing down of nitrate-rich air from the RL aloft. Young et al. (2016) and Parworth et al. (2017) observed similar behavior more than a decade later during DISCOVERAQ in 2013. Pusede et al. (2016) characterized the relationship between long-term (multiyear) surface measurements of wintertime $\mathrm{NO}_{3}^{-}(\mathrm{p})$ and $\mathrm{NO}_{2}$ in Fresno and Bakersfield and showed that the decline in $\mathrm{NO}_{3}^{-}$(p) in the SJV over time (2001-2012) was predominately driven by reduced nocturnal $\mathrm{NO}_{3}^{-}$(p) production in the residual layer. The balance between production, especially nighttime production, and daytime losses was identified by them as critical to understanding the multiday buildup during pollution events. Further, they concluded from DISCOVER-AQ aircraft measurements that much of the $\mathrm{NO}_{3}^{-}$(p) production was localized over the cities given the sharp urban-rural gradients in $\mathrm{NO}_{3}^{-}(\mathrm{p})$; the spatial gradients in 2013 (from Pusede et al., 2016) seem to be sharper than gradients in 2000 (from Chow et al., 2006), likely reflecting the increasing localization of the $\mathrm{NO}_{3}^{-}(\mathrm{p})$ pollution to the urban centers as overall $\mathrm{NO}_{3}^{-}$(p) concentrations in the region have decreased. Brown et al. (2006a) ob- served that the number concentration of accumulation mode particles $(0.32-1.07 \mu \mathrm{m})$ often increased above the surface at $90 \mathrm{~m}$ a.g.l. compared to surface $(7 \mathrm{~m} \mathrm{a.g.l}$.) measurements during night and suggested that this was due to the growth of smaller particles into the accumulation mode via $\mathrm{NO}_{3}^{-}(\mathrm{p})$ formation. They also observed that the concentration of $\mathrm{NO}_{3}^{-}(\mathrm{p})$ at $90 \mathrm{~m}$ a.g.l. often increased at night, which is suggestive of in situ production.

The present study builds on this literature by examining the role that aloft nocturnal nitrate production, in concert with other processes, has in determining surface $\mathrm{NO}_{3}^{-}(\mathrm{p})$ concentrations during the DISCOVER-AQ campaign that took place in January and February 2013 in the SJV. Our study combines aircraft and surface observations from DISCOVER-AQ (Fig. S2). During DISCOVER-AQ, two pollution episodes were observed during which $\mathrm{PM}_{2.5}$ concentrations were elevated (Young et al., 2016). The analysis here focuses on the quantitative assessment of $\mathrm{NO}_{3}^{-}$(p) concentrations during this first episode (14-22 January) in terms of the processes that govern the $\mathrm{NO}_{3}^{-}(\mathrm{p})$ diurnal behavior; the observed behavior during this first episode is qualitatively compared with that during the second episode (30 January6 February) to examine the factors that contribute to episodeto-episode variability. On flight days, in situ measurements of the vertical profiles of particulate and gas concentrations above Fresno (and other SJV cities) were made three times: in the midmorning $(\sim 09: 30 \mathrm{LT})$, around noon and in the midafternoon $(\sim 14: 00 \mathrm{LT})$. These measurements allow for the assessment of the daytime evolution of the vertical distribution of PM and gases as well as characterization of the time-varying boundary layer height (BLH). They also allow for the determination of the overnight evolution of the PM vertical distribution, which can be used to characterize the factors that control $\mathrm{NO}_{3}^{-}$(p) concentrations in the RL. The influence of processes occurring aloft on the temporal evolution of $\mathrm{NO}_{3}^{-}$(p) surface concentrations is quantitatively evaluated for this case study using an observationally constrained 1-D box model. The box model accounts for both vertical mixing (entrainment) of air to the surface and for photochem- 
ical $\mathrm{NO}_{3}^{-}$(p) production, as well as $\mathrm{NO}_{3}^{-}$(p) loss processes. Ultimately, the observations and analysis further illustrate how daytime surface-level $\mathrm{NO}_{3}^{-}$(p) concentrations depend on a combination of both nocturnal and daytime production of $\mathrm{NO}_{3}^{-}(\mathrm{p})$, vertical mixing, altitude-dependent advection in the RL overnight, daytime entrainment of clean air from the free troposphere (FT) and evaporation-driven dry deposition. The model and observations are used to examine the relative importance of these different pathways during the case-study episode considered. This work adds to the existing literature by providing an observationally based, case-study demonstration of how nocturnal processes occurring aloft - in concert with other processes - exert a major control over the evolution of pollution episodes within the SJV specifically and likely in other regions as well.

\section{Materials and method}

Airborne in situ measurements (such as particle scattering; gas-phase concentrations; relative humidity, $\mathrm{RH}$; and temperature) during the DISCOVER-AQ campaign were made by a suite of instruments onboard the P3-B NASA aircraft. The flight path flown during each of the three legs for each flight day is shown in Fig. S2. The aircraft measurements were complemented by a network of ground measurement sites, of which Fresno was one. At Fresno, continuous, in situ measurements of the chemical composition and physical properties of particulate matter were performed along with measurements of NAAQS-regulated pollutants (Young et al., 2016; Zhang et al., 2016; Parworth et al., 2017). Local conditions during DISCOVER-AQ were relatively cool $\left(T_{\text {avg }}=7.9^{\circ} \mathrm{C}\right)$ and dry $\left(\mathrm{RH}_{\mathrm{avg}}=69 \%\right)$ with frequent sunshine and no visible fog. All data are archived at the DISCOVER-AQ website (NASA Atmospheric Science Data Center). Details of all measurements made are provided in Appendix A and summarized in Table A1.

\section{Results and discussion}

\subsection{Vertical distribution of $\mathrm{NO}_{3}^{-}(p)$}

The concentration and vertical distribution of $\mathrm{NO}_{3}^{-}$(p) in the $\mathrm{RL}\left(\left[\mathrm{NO}_{3}^{-}(\mathrm{p})\right]_{\mathrm{RL}}\right)$ in the morning serves as the initial condition constraint on what is mixed down to the surface as the day advances and the ML rises. Thus, knowledge of the vertical distribution of $\mathrm{NO}_{3}^{-}(\mathrm{p})$ in the $\mathrm{RL}$ near sunrise is needed to predict the temporal evolution of surface-level $\mathrm{NO}_{3}^{-}(\mathrm{p})$ during the daytime, as will be done below. Nighttime flights were not made during DISCOVER-AQ to allow for the characterization of the overnight evolution of the RL. However, the early-morning ( 09:30 LT) vertical profiles over Fresno allow for the characterization of the vertical structure of most of the RL near sunrise ( $\sim 07: 10 \mathrm{LT})$, as the surface boundary layer height at this point is still quite shallow $(\sim 50 \mathrm{~m}$; see Appendix B for a description of the mixed boundary layer height determination method, Figs. B1-B2). Fast measurements of total $\mathrm{NO}_{3}^{-}$(gas + particle, $\mathrm{NO}_{3}^{-}(\mathrm{g}+\mathrm{p})$ ) were only available for a subset of flights (Pusede et al., 2016), and particulate-only $\mathrm{NO}_{3}^{-}$measurements were not made with sufficient time resolution, less than about a minute, to allow for robust characterization of the $\mathrm{NO}_{3}^{-}$(p) vertical profile. Therefore, $\mathrm{NO}_{3}^{-}(\mathrm{p})$ vertical profiles for each flight during Episode 1 are estimated from in situ measurements of dry particle scattering and the influence of water uptake on scattering, i.e., from the particle hygroscopicity, and are calibrated against the slower particle-into-liquid sampler (PILS) measurements (Appendix A, Fig. A1). The derived, observationally constrained $\mathrm{NO}_{3}^{-}(\mathrm{p})$ profiles based on the estimated $\mathrm{NO}_{3}^{-}(\mathrm{p})$ exhibit generally good correspondence with the sparser direct measurements of $\mathrm{NO}_{3}^{-}(\mathrm{g}+\mathrm{p})$, although on 1 of the 2 days available for comparison the total $\mathrm{NO}_{3}^{-}$somewhat exceeds the estimated $\mathrm{NO}_{3}^{-}$(p) below $\sim 75 \mathrm{~m}$ (Fig. 2). This indicates that the estimation method is reasonable, especially since most nitrate is expected to be in the particle phase (Parworth et al., 2017) given the high relative total ammonium $\left(\mathrm{NH}_{3}+\mathrm{NH}_{4}^{+}\right)$concentrations (Fig. 3). Only 4 out of 5 flight days during Episode 1 have been included in this analysis due to insufficient data on 16 January.

Over Fresno, the observed afternoon $(\sim 14: 30 \mathrm{LT}) \mathrm{NO}_{3}^{-}$(p) concentrations are nearly constant with altitude up to $\sim 400 \mathrm{~m}$ (the daytime boundary layer height) (Fig. 2b), whereas the early-morning $\mathrm{NO}_{3}^{-}(\mathrm{p})$ concentrations decrease steeply with altitude up to $\sim 350 \mathrm{~m}$ (Fig. 2a). Corresponding vertical profiles for $\mathrm{NO}, \mathrm{NO}_{2}, \mathrm{O}_{3}$, relative humidity, temperature and total particle scattering are shown in Figs. S2 (early morning) and $\mathrm{S} 3$ (afternoon). Like $\mathrm{NO}_{3}^{-}(\mathrm{p}$ ), all indicate substantial differences between the early-morning and afternoon profile shapes. This provides a strong indication that altitudespecific processes occur overnight that lead to a reshaping of the $\mathrm{NO}_{3}^{-}(\mathrm{p})$ vertical profile. At some altitudes the $\mathrm{NO}_{3}^{-}(\mathrm{p})$ in the early-morning $\mathrm{RL}$ is greater than the $\mathrm{NO}_{3}^{-}(\mathrm{p})$ measured in the previous afternoon, indicating net production, while at other altitudes the early-morning $\mathrm{RL} \mathrm{NO}_{3}^{-}$(p) is less than the previous afternoon, indicating net loss (Fig. 2). As noted by Pusede et al. (2016), there tend to be sharp concentration gradients in $\mathrm{NO}_{3}^{-}$(p) and $\mathrm{NO}_{x}$ between the city and surrounding areas, with lower concentrations outside the city. Thus, whether $\mathrm{NO}_{3}^{-}(\mathrm{p})$ at a given altitude increases or decreases overnight results from the competing effects of chemical production versus horizontal advection bringing in this (typically) cleaner air from outside the city. (In the absence of a strong jet aloft and no convective mixing, nighttime entrainment of cleaner FT air into the RL is expected to be considerably slower than horizontal advection.) Like $\mathrm{NO}_{3}^{-}(\mathrm{p})$, the boundary layer is reasonably well mixed with respect to $\mathrm{NO}_{x}, \mathrm{O}_{3}$ and particles at the time when decoupling of the RL occurs around 15:00 LT the previous day (Fig. S4). Box model calculations indicate that the expected local nocturnal chemical production of nitrate in the RL should exhibit rel- 

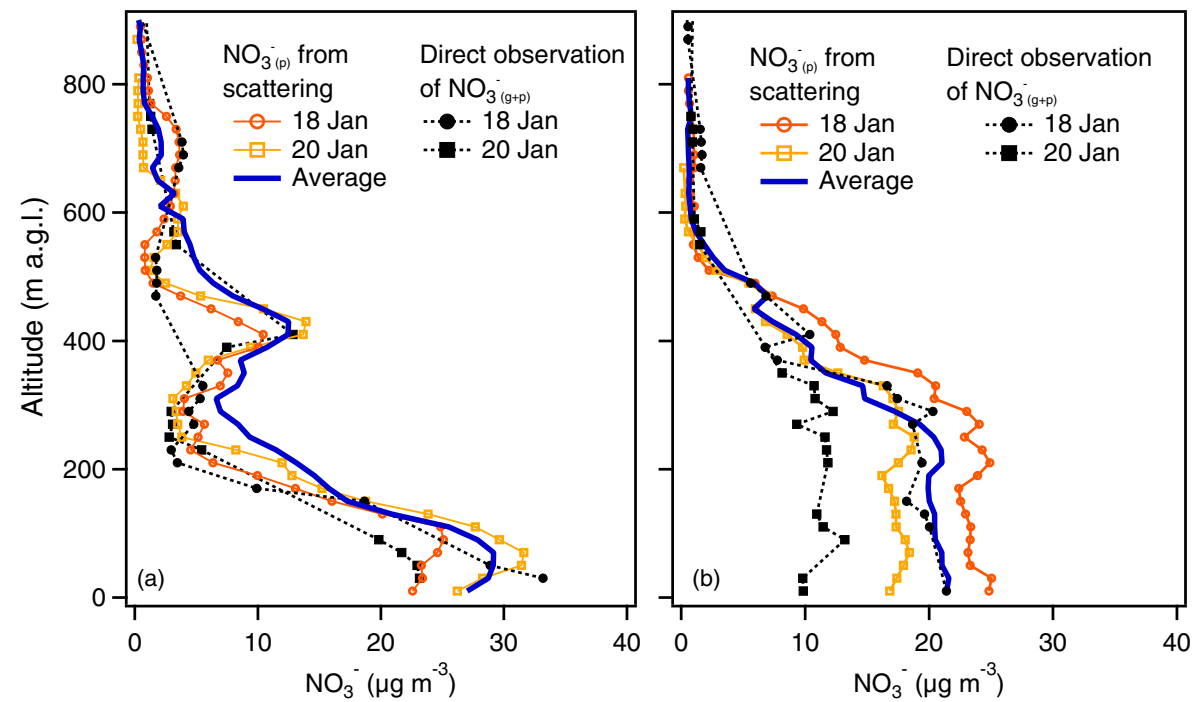

Figure 2. Vertical profiles for 2 individual flight days of particulate nitrate concentrations estimated from in situ total particle scattering measurements (open markers) and total nitrate (gas + particle) concentrations measured by the TD-LIF (solid black markers) for (a) the morning $(\sim 09: 30 \mathrm{LT})$ and $(\mathbf{b})$ the afternoon $(\sim 14: 30 \mathrm{LT})$. The solid blue lines indicate the average $\mathrm{NO}_{3}^{-}$(p) vertical profiles for all 4 flight days of Episode 1 (18, 20, 21 and 22 January).

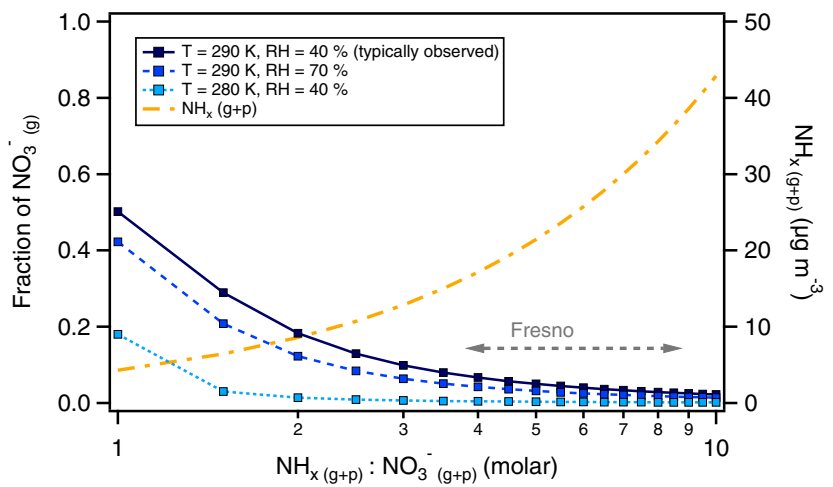

Figure 3. The gaseous fraction of total nitrate versus the molar ratio of total ammonia to total nitrate ( $\mathrm{ppb}$ ) under different environmental conditions (blue lines). The total ammonia is the sum of $\mathrm{NH}_{3}(\mathrm{~g})$ measured on the P3-B close to ground ( $<20$ m a.g.1.) and $\mathrm{NH}_{4}^{+}(\mathrm{p})$ at ground level measured by PILS at approximately same time. The total nitrate is the $\mathrm{NO}_{3}^{-}(g+p)$ measured by TD-LIF close to ground $(<20 \mathrm{~m}$ a.g.1.). The gray dashed arrow indicates the observed range of molar ratio values during the campaign period. The total (gas + particle) ammonia is shown for reference (orange line).

atively minor vertical variation due to variations in temperature and RH alone (Fig. S5). In other words, without advective loss or dilution processes of either $\mathrm{NO}_{3}^{-}(\mathrm{p})$ or the precursor gases, it is expected that the $\mathrm{NO}_{3}^{-}$(p) concentration would increase to a similar extent at all RL altitudes.

The substantial changes observed in the shape of the vertical profile overnight indicate that nighttime differential advection in the RL is a major factor in determining the shape of the morning $\mathrm{NO}_{3}^{-}(\mathrm{p})$ vertical profile during this pollution episode. Differential horizontal advection serves to directly export $\mathrm{NO}_{3}^{-}$(p) from the urban area and import cleaner air from surrounding areas. Secondarily, as $\mathrm{NO}_{x}$ concentrations are also lower outside of the Fresno urban area (Pusede et al., 2014), this differential advection will also influence the over-city concentrations of precursors gases $\left(\mathrm{NO}_{x}\right.$ and $\mathrm{O}_{3}$; Figs. S3-S4) and consequently the altitude-specific nitrate production, with decreases likely. This is supported by surface-level measurements of $\mathrm{NO}_{x}$ and $\mathrm{O}_{3}$ made in Fresno and in the nearby and much more rural cities of Parlier (located $35 \mathrm{~km}$ SE of Fresno) and Madera (located $40 \mathrm{~km} \mathrm{NW}$ of Fresno). The $\mathrm{NO}_{x}$ and $\mathrm{NO}_{2}$ concentrations are higher and the $\mathrm{O}_{3}$ lower in Fresno compared to the surrounding cities throughout the day, and the instantaneous nitrate production rate $\left(\left[\mathrm{NO}_{2}\right]\left[\mathrm{O}_{3}\right]\right)$ is substantially higher in Fresno in the late afternoon, when decoupling occurs (Fig. S6). The important implication is that overnight advection both directly and indirectly alters the vertical $\mathrm{NO}_{3}^{-}$(p) profile and decreases the over-city $\mathrm{NO}_{3}^{-}(\mathrm{p})$ concentrations in the morning, which will consequently serves to limit the extent of localized pollution buildup during events. The impact of overnight differential advection on reshaping the vertical distribution of $\mathrm{NO}_{3}^{-}(\mathrm{p})$ has likely increased over the last 15 years as the sharpness of the urban-rural concentration gradients has increased (Chow et al., 2006; Pusede et al., 2016). Nonetheless, the $\mathrm{NO}_{3}^{-}$(p) advected from urban areas in the RL will contribute to the regional SJV background and serve to sustain $\mathrm{NO}_{3}^{-}$(p) levels across the valley during pollution episodes.

In the summer, transport and dispersion of pollutants has been attributed to low-level winds (less than $500 \mathrm{~m}$ a.g.l.) 

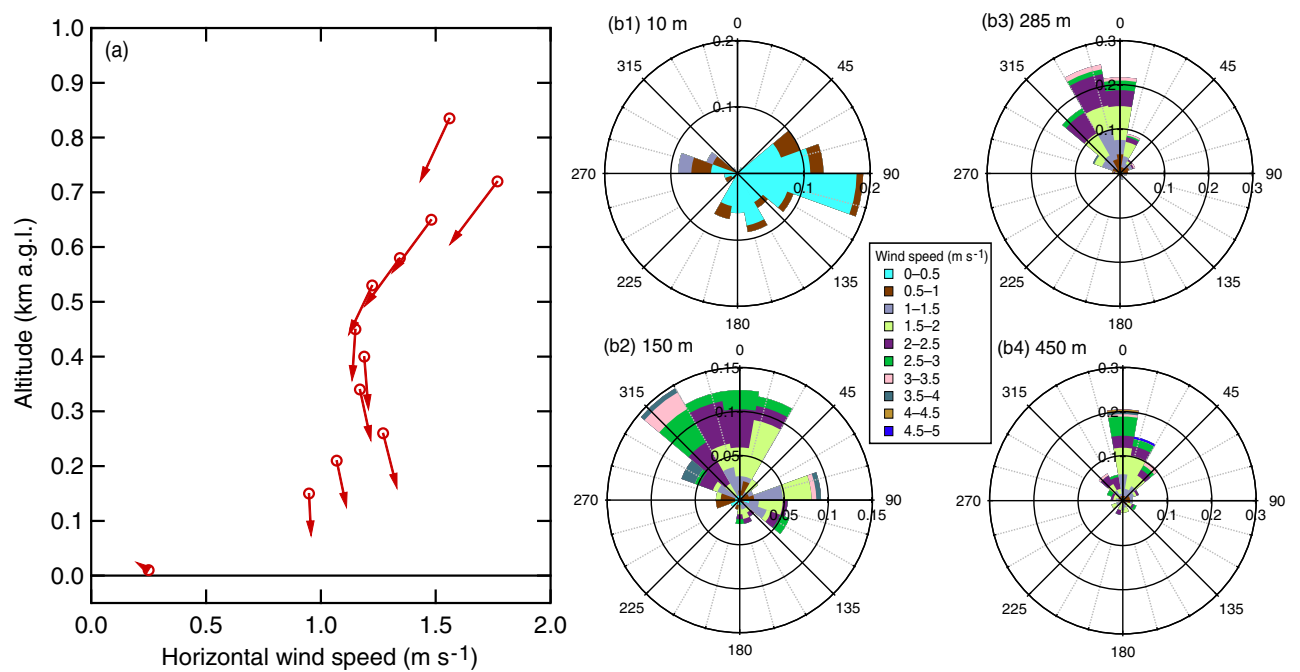

Figure 4. (a) Vertical profile of the average nighttime (19:00-07:00) horizontal winds over Visalia, CA (65 km SE of Fresno), and the surface $(10 \mathrm{~m})$ wind in Fresno for flight days during Episode 1 (18, 20, 21 and 22 January). The length of the arrows corresponds to the wind speed and the direction to the average wind direction, with the measurement height indicated by the circle on the tail of the arrow. (b) Corresponding wind roses for (b1) the surface, (b2) 125-175 m, (b3) 225-345 m and (b4) 400-500 m. The length of each arc corresponds to the normalized probability and the colors indicate the wind speed $\left(\mathrm{m} \mathrm{s}^{-1}\right.$; see legend). Data are from the National Oceanic and Atmospheric Administration, Earth System Research Laboratory, Physical Sciences Division Data and Image Archive (https://www.esrl. noaa.gov/psd/data/obs/datadisplay/, accessed 3 June 2017).

in the SJV (Bao et al., 2008). We suggest that a similar, but weaker, circulation may exist even in the winter, just at much slower wind speeds, and that this advection overnight is what leads to differential washout and the establishment of the particular vertical $\mathrm{NO}_{3}^{-}(\mathrm{p})$ concentration profiles in the $\mathrm{RL}$. The concentration of $\mathrm{NO}_{3}^{-}$(p) will likely be lowest in the early-morning RL at altitudes where horizontal advection has the greatest impact. Wind profiler measurements made in nearby Visalia, CA ( $65 \mathrm{~km} \mathrm{SE}$ of Fresno), indicate that during the night (19:00-07:00) there was local maximum in the mean wind speed at $\sim 250 \mathrm{~m}$, which is around the altitude at which the early-morning $\mathrm{NO}_{3}^{-}(\mathrm{p})$ concentration is minimum (Fig. 2a). Below $250 \mathrm{~m}$ there was a monotonic increase in the nighttime mean wind speed with altitude, with very slow speeds observed at the surface. Above $250 \mathrm{~m}$ the mean wind speed was relatively constant to $\sim 450 \mathrm{~m}$, above which it increased with altitude. Explicit comparison between the vertical profiles of nighttime mean wind speed and the estimated early-morning $\mathrm{NO}_{3}^{-}$(p) concentration indicates an inverse relationship $(r=-0.98)$ between the two (Fig. S7). This is consistent with the idea that differential advection as a function of altitude overnight serves to shape the earlymorning concentration profiles. The wind direction at lower altitudes $(\sim 150 \mathrm{~m})$ was generally more variable than those at higher altitudes ( 285 or $450 \mathrm{~m}$ ), with a general shift from more westerly at lower altitudes (but above the surface) to more northerly near the top of the RL (Fig. 4b). (Note that vector average wind speeds for each individual night were calculated and then a scalar average of these night-specific vector averages was calculated to give the episode average mean wind speeds. This averaging process emphasizes directional consistency of the winds on a given night, but not between nights.) The increase in $\mathrm{NO}_{3}^{-}$(p) concentration at $\sim 400 \mathrm{~m}$ a.g.l. in the early-morning profile, especially noticeable on 21 January (Fig. S8), could result from a slowing of the winds near the top of the RL or from enhanced recirculation of pollutants at higher altitudes. Regardless of reason, this work indicates that the gradient between the local (above city) and regional $\mathrm{NO}_{3}^{-}(\mathrm{p})$ and precursor gases, evident in Pusede et al. (2016), is an important factor in determining the nighttime evolution of the RL vertical profile. Explicit characterization of the temporal evolution of the vertical structure of $\mathrm{NO}_{3}^{-}$(p) within the nighttime $\mathrm{RL}$ would provide further insights into the altitude-specific processes that control the shape of the early-morning profile (and thus the concentration of $\mathrm{NO}_{3}^{-}(\mathrm{p})$ aloft that can be mixed to the surface in daytime).

The difference between the concentration of $\mathrm{NO}_{3}^{-}(\mathrm{p})$ at each altitude of the early-morning vertical profile and that at 15:00 LT on the preceding afternoon $\left(\Delta\left[\mathrm{NO}_{3}^{-}(\mathrm{p})\right]_{\mathrm{RL}}\right)$ yields the net overnight $\mathrm{NO}_{3}^{-}$production or loss in the RL. If it is assumed that the layer with the highest $\mathrm{NO}_{3}^{-}$(p) is not influenced by advection, then the $\Delta\left[\mathrm{NO}_{3}^{-}(\mathrm{p})\right]_{\mathrm{RL}}$ in this layer provides an estimate of the maximum chemical production $\left(P \mathrm{NO}_{3}^{-}\right)$. This estimate of $\mathrm{PNO}_{3}^{-}$is certainly a lower bound on actual nitrate formation given the assumption of no influence of horizontal advection, and this also does not account for produced nitrate that remains in the gas phase (although 
this is likely to be small). On average, the observations indicate that chemical production overnight in the RL leads to an approximate doubling over the initial $\mathrm{NO}_{3}^{-}(\mathrm{p})$ concentration, or $10-25 \mu \mathrm{g} \mathrm{m}^{-3}$ of $\mathrm{NO}_{3}^{-}$(p) produced over the course of the night for this episode (Table S1 in the Supplement). Observed day-to-day variability in $\mathrm{PNO}_{3}^{-}$likely results from day-to-day variations in precursor $\left(\mathrm{NO}_{x}\right.$ and $\left.\mathrm{O}_{3}\right)$ concentrations and $\mathrm{N}_{2} \mathrm{O}_{5}$ reactivity, as well as limitations of the assumption of no advection in this layer. To assess the reasonableness of this estimate of $\mathrm{PNO}_{3}$ as a maximum production rate, values of the night-specific average rate coefficients for

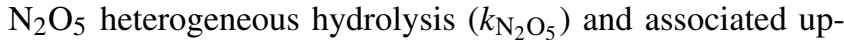
take coefficients $\left(\gamma_{\mathrm{N}_{2} \mathrm{O}_{5}}\right)$ needed to reproduce the observed $\mathrm{PNO}_{3}^{-}$are back calculated based on the initial $\mathrm{NO}_{x}, \mathrm{O}_{3}$, and wet particle surface area, and assuming $\mathrm{ClNO}_{2}$ formation is negligible (see Appendix $\mathrm{C}$ and Table S1). The derived $k_{\mathrm{N}_{2} \mathrm{O}_{5}}$ values range from 1.3 to $5.1 \times 10^{-5} \mathrm{~s}^{-1}$ with corresponding $\gamma_{\mathrm{N}_{2} \mathrm{O}_{5}}$ from $2.5 \times 10^{-4}$ to $4.8 \times 10^{-4}$. These are smaller than values observed under water-limited conditions in other field studies (Brown et al., 2006c; Bertram et al., 2009) and lower than expected based on lab experiments (Bertram et al., 2009). $\gamma_{\mathrm{N}_{2} \mathrm{O}_{5}}$ values separately calculated from the particle composition measurements, following Bertram et al. (2009), are larger than the above backcalculated values, with $\gamma \mathrm{N}_{2} \mathrm{O}_{5} \sim 10^{-3}$, and more consistent with the literature. This suggests that the $\mathrm{PNO}_{3}^{-}$is, in fact, a lower estimate and that the $\mathrm{NO}_{3}^{-}$(p) concentration in even the lower layers of the RL is influenced by advection. Box model calculations using the (too low) back-calculated $k_{\mathrm{N}_{2} \mathrm{O}_{5}}$ and $\gamma_{\mathrm{N}_{2} \mathrm{O}_{5}}$ yield $\sim 15-42 \% \mathrm{NO}_{x}$ conversion to $\mathrm{HNO}_{3}$ overnight during this episode. If instead $\gamma_{\mathrm{N}_{2} \mathrm{O}_{5}}=10^{-3}$ is used, the calculated overnight conversion is somewhat larger, $\sim 52 \%$. Also, if $k_{\mathrm{N}_{2} \mathrm{O}_{5}}$ and $\gamma_{\mathrm{N}_{2} \mathrm{O}_{5}}$ were assumed to be sufficiently large such that they are not rate limiting the overnight conversion would increase further to $\sim 63 \%$. It should be noted that during this episode the surface $\mathrm{O}_{3}$ overnight is essentially completely titrated away by 18:00 LT (Fig. 5). The reaction between $\mathrm{NO}_{2}$ and $\mathrm{O}_{3}$ (Reaction R1) is thus very slow and nighttime chemical production of $\mathrm{NO}_{3}^{-}$(p) at the surface in the NBL is comparably small.

\subsection{Vertical mixing, photochemical production and $\mathrm{NO}_{3}^{-}(\mathrm{p})$ sinks}

The observed episode average-surface-level $\mathrm{NO}_{3}^{-}(\mathrm{p})$ concentration exhibits a distinct, rapid increase starting at $\sim 08: 00 \mathrm{LT}$, then peaks around 10:00-11:00 LT and decreases fairly continuously after the peak, especially between 13:00 and 16:00 LT (Fig. 6a). For reference, time series of $\mathrm{NO}_{3}^{-}(\mathrm{p})$ during the pollution episode, along with $\mathrm{CO}, \mathrm{NO}$, $\mathrm{NO}_{2}, \mathrm{O}_{3}$, temperature, surface radiation and $\mathrm{PM}_{1}$, are shown in Fig. S9. Both Young et al. (2016) and Pusede et al. (2016) noted this increase, arguing it is a signature of nocturnal nitrate production. Here, we provide a more detailed examination of the specific influence of vertical mixing and nocturnal

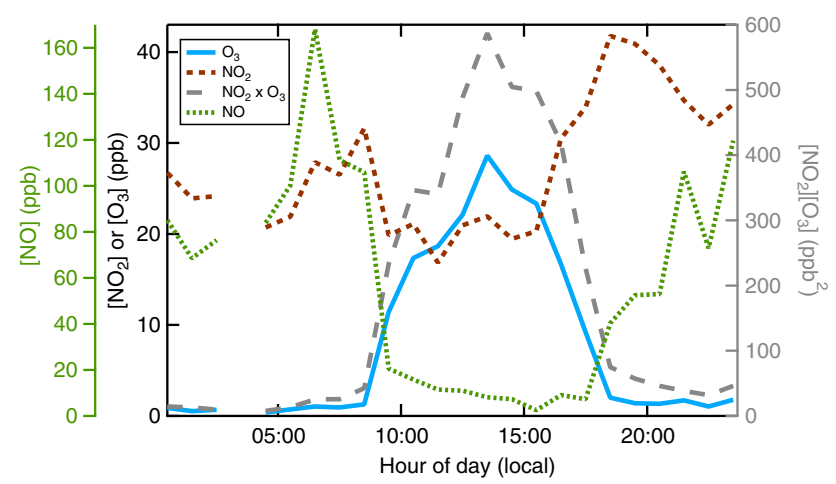

Figure 5. Diurnal profiles for ozone (blue), $\mathrm{NO}_{2}$ (brown), $\mathrm{NO}$ (green), and the product of $\mathrm{O}_{3}$ and $\mathrm{NO}_{2}$ (gray) for the first pollution episode.

$\mathrm{NO}_{3}^{-}$(p) production in the $\mathrm{RL}$ on the observed daytime variability in surface-level $\mathrm{NO}_{3}^{-}(\mathrm{p})$ using an observationally constrained one-dimensional box model (see Appendix D for details). In brief, the model accounts for time-dependent mixing between air in the mixed boundary layer and the RL, daytime photochemical production of nitrate, gas-particle partitioning of nitrate, entrainment of clean air from the free troposphere into the ML and loss of nitrate via dry deposition to calculate the time-dependent evolution of the surface-level $\mathrm{NO}_{3}^{-}$(p) concentration. The observed vertical profiles of $\mathrm{NO}_{3}^{-}$(p) concentrations in the RL (referred to as $\left[\mathrm{NO}_{3}^{-}(\mathrm{p})\right]_{\mathrm{RL}}$ and taken as the observed early-morning and noon profiles) provide a unique constraint for understanding and quantifying the influence of vertical mixing specifically, allowing us to expand on previous studies. The model is additionally constrained by the surface-level concentrations of $\mathrm{NO}_{2}$ and $\mathrm{O}_{3}$, as well as temporally varying $\mathrm{ML}$ height. The evolution of the daytime ML height and rate of entrainment are determined using the Chemistry Land-surface Atmosphere Soil Slab model (CLASS; https://classmodel.github.io/; Ouwersloot and VilàGuerau de Arellano, 2013). The CLASS model is constrained by observations of the time-dependent vertical profile measurements of temperature, $\mathrm{RH}$ and other gas-phase species over Fresno and by $T$ and RH profiles and surface sensible heat flux measurements at nearby Huron, CA $(\sim 83 \mathrm{~km}$ SSW of Fresno) (Appendix B). Starting at around 08:00 LT, the ML begins to grow vertically by entraining air from the RL. It is assumed that air within the ML is instantaneously mixed throughout the volume. Within the (shrinking) $\mathrm{RL}$ the $\mathrm{NO}_{3}^{-}(\mathrm{p})$ is assumed to retain the initial profile shape until it reaches the maximum ML height observed in the afternoon $(\sim 12: 30 \mathrm{LT})$. After this point entrainment of free-tropospheric air begins. The concentration of $\mathrm{NO}_{3}^{-}(\mathrm{p})$ in FT air is determined from the vertical profile observed around noon. While entrainment of FT air also alters the $\mathrm{NO}_{2}$ and $\mathrm{O}_{3}$ concentrations in the mixed layer, since these are constrained by the surface observations (within the mixed layer), this is accounted for. Photochemical production of 

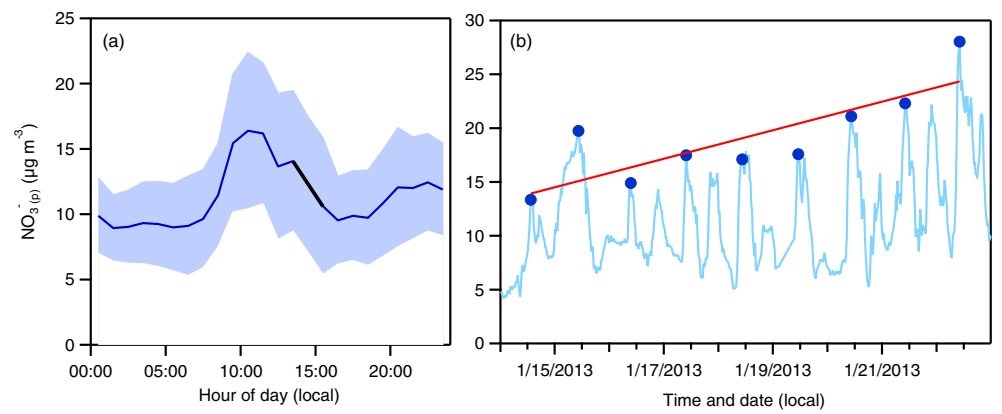

Figure 6. (a) Average diurnal profile (solid line) of surface $\mathrm{NO}_{3}^{-}$(p) for all days of Episode 1 . The shaded area indicates the $1 \sigma$ standard deviation. The solid black line is a linear fit $\left(r^{2}=0.99\right)$ to the data between 13:30 and 15:30 LT. (b) Time series (solid blue line) of surfacelevel $\mathrm{NO}_{3}^{-}(\mathrm{p})$ during Episode 1 . The circles indicate the daytime peak values. The linear fit (red line) to the daytime $\mathrm{NO}_{3}^{-}(\mathrm{p})$ peaks suggest an increase of $1.32 \mu \mathrm{g} \mathrm{m}^{-3}$ day $^{-1}$.

$\mathrm{HNO}_{3}$ is calculated based on the oxidation of $\mathrm{NO}_{2}$ by hydroxyl radicals, with wintertime concentrations estimated to peak around $[\mathrm{OH}]=10^{6}$ molecules $\mathrm{cm}^{-3}$ at noon in the region, with contributions from $\mathrm{O}\left({ }^{1} \mathrm{D}\right)+\mathrm{H}_{2} \mathrm{O}$ (from $\mathrm{O}_{3}$ photolysis), $\mathrm{HONO}$ photolysis and $\mathrm{CH}_{2} \mathrm{O}$ photolysis (Pusede et al., 2016). The $\mathrm{OH}$ concentration is assumed to scale linearly with the observed solar radiation (Fig. S10).

The average calculated daytime temporal evolution of surface $\mathrm{NO}_{3}^{-}$(p) from the observationally constrained box model agrees reasonably well with the average of the surface observations from the 4 Episode 1 flight days considered (Fig. 7a). (The observed diurnal average in Fig. 6 uses all of the days from Episode 1, whereas in Fig. 7 only 4 flight days are included. This is because the initial early-morning $\mathrm{NO}_{3}^{-}(\mathrm{p}$ ) vertical profile is required as input to the model.) The model predictions for the individual flight days also exhibit generally good agreement with the $\mathrm{NO}_{3}^{-}$(p) observations except in the late evening, which is discussed further below (Fig. S8). Specifically, the observationally constrained model also shows a rapid increase in $\mathrm{NO}_{3}^{-}$(p) beginning at 08:00 LT, a peak around 10:00-11:00 LT and a gradual, time-varying decrease through the afternoon.

Consideration of the individual processes occurring in the model demonstrates that the vertical mixing down of $\left[\mathrm{NO}_{3}^{-}(\mathrm{p})\right]_{\mathrm{RL}}$ and the shape of the $\left[\mathrm{NO}_{3}^{-}(\mathrm{p})\right]_{\mathrm{RL}}$ vertical profile predominately control the morning-time evolution of the surface $\mathrm{NO}_{3}^{-}$(p) during this episode (Figs. 7 and 8). The particularly steep rise in the surface-level $\mathrm{NO}_{3}^{-}$(p) in the morning results from the combination of the NBL height being exceptionally shallow (only $\sim 20 \mathrm{~m}$ ) and the $\mathrm{NO}_{3}^{-}$(p) in the lowaltitude region of the RL being greater than the $\mathrm{NO}_{3}^{-}(\mathrm{p})$ in the early-morning NBL. The peak and turnover in surfacelevel $\mathrm{NO}_{3}^{-}(\mathrm{p})$ occurs when even higher RL layers, where $\left[\mathrm{NO}_{3}^{-}(\mathrm{p})\right]_{\mathrm{RL}}<\left[\mathrm{NO}_{3}^{-}(\mathrm{p})\right]_{\mathrm{ML}}$, are entrained. In other words, the temporal evolution of the surface-level $\mathrm{NO}_{3}^{-}(\mathrm{p})$ is linked to the shape of the early-morning vertical $\mathrm{NO}_{3}^{-}$profile. Further, it should be noted that the exact model behavior is dependent on the timing of the CLASS-predicted boundary layer height increase, with the initial increase and timing of the surface-level $\mathrm{NO}_{3}^{-}$(p) peak being particularly sensitive to the shape of the rise between 08:00 and 10:00 LT. Nonetheless, because the NBL is so shallow here, only $\sim 3-12 \%$ of the daytime ML height, the surface concentration is strongly impacted by the concentrations in the RL and the initial (pre08:00 LT) surface-level nitrate has control over daytime concentrations. Thus, the model results demonstrate that the observation of the large 10:00 LT peak in $\mathrm{NO}_{3}^{-}(\mathrm{p})$ is a clear indication of the strong influence of nocturnal processes occurring aloft - both chemical production and advection-driven local loss - on daytime surface concentrations.

As an extreme counterexample, if there were no $\mathrm{NO}_{3}^{-}(\mathrm{p})$ in the RL, mixing would have led to an initial decline in the early-morning surface $\mathrm{NO}_{3}^{-}$(p) (Fig. 8a). Alternatively, if the aloft $\mathrm{NO}_{3}^{-}$(p) concentration were assumed to be equal to that from the previous day at 15:00 LT (and with no vertical variability), there would not have been a sharp increase in the morning surface $\mathrm{NO}_{3}^{-}$(p) (Fig. 8b). Instead, there would have been a more gradual increase from the morning into the afternoon due largely to the increasing influence of photochemical production. This is representative of a case in which there was neither aloft production of $\mathrm{NO}_{3}^{-}(\mathrm{p})$ nor losses from advection, such that the early-morning RL concentration was determined entirely by carryover from the prior day; in this case the difference between the early-morning surface concentration and that in the RL is small compared to the observations. If, instead, the $\mathrm{RL} \mathrm{NO}_{3}^{-}$(p) concentration at all altitudes had been equal to the maximum $\mathrm{NO}_{3}^{-}$(p) observed in the RL (no vertical gradient in the RL), then the morning peak in surface-level $\mathrm{NO}_{3}^{-}$(p) would have occurred later and the $\mathrm{NO}_{3}^{-}$(p) concentration would be substantially higher throughout a greater fraction of the day (Fig. 8c). This is representative of a case in which nocturnal production in the RL occurred, but where advection did not serve to reshape the $\mathrm{NO}_{3}^{-}$(p) vertical profile in the RL. Clearly, export of pollution from the relatively compact Fresno urban area to the broader region (and import of cleaner air) plays an important 

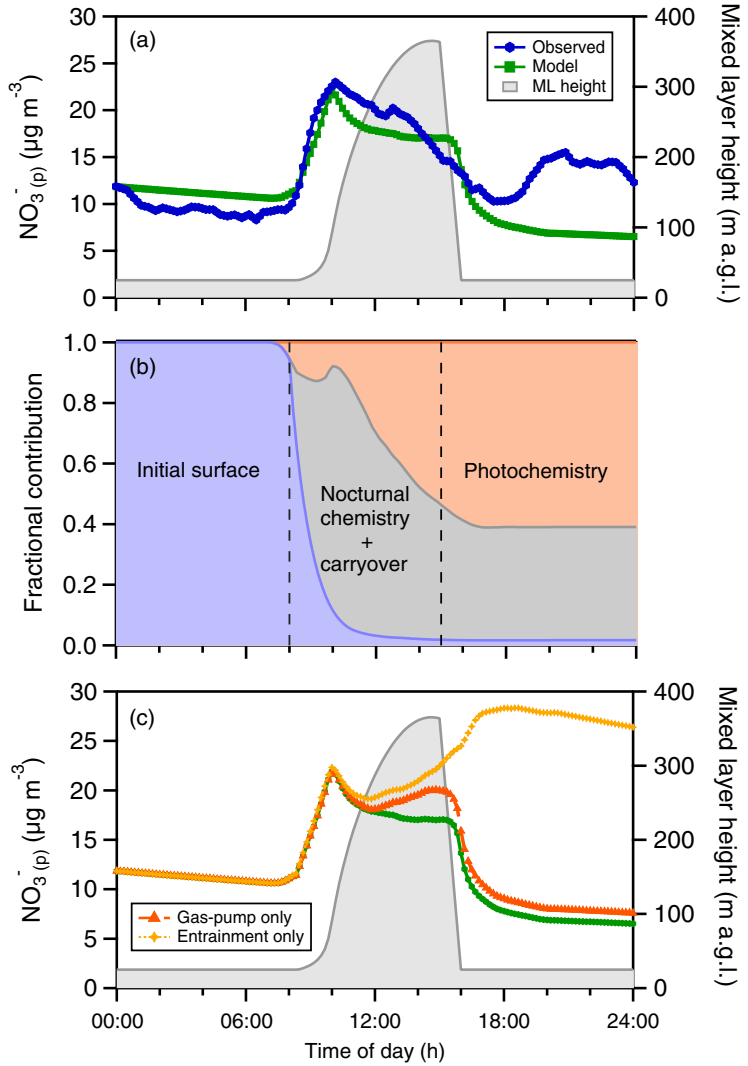

Figure 7. (a) Comparison between the observed (blue circles) and observationally constrained model-predicted (green squares) diurnal profile of the surface $\mathrm{NO}_{3}^{-}(\mathrm{p})$ concentration $\left(\mu \mathrm{g} \mathrm{m}^{-3}\right)$ for the 4 flight days (18, 20, 21 and 22 January, 2013) during Episode 1. Also shown is the diurnal variation in the boundary layer height (gray), as constrained by daytime measurements. (b) The diurnal variation in the simulated fraction of the total surface-level $\mathrm{NO}_{3}^{-}(\mathrm{p})$ contributed by the initial surface-level $\mathrm{NO}_{3}^{-}$(p) (i.e., that at the surface level at 00:00 LT), the $\mathrm{NO}_{3}^{-}$(p) mixed down from the $\mathrm{RL}$ and $\mathrm{NO}_{3}^{-}$(p) produced from daytime photochemical reactions. (c) Comparison between the simulated diurnal profile when all processes are included (green squares, same as panel a) and when only one $\mathrm{NO}_{3}^{-}$(p) sink at a time is considered. The individual sinks considered are only entrainment of free-troposphere air (yellow crosses) or only dry deposition of $\mathrm{HNO}_{3}$ via the gas-phase pump (orange triangles).

role in determining the daytime surface-level concentration of $\mathrm{NO}_{3}^{-}(\mathrm{p})$, multiday buildup and the population exposure in this urban area. While it has previously been suggested that the morning increase in surface-level $\mathrm{NO}_{3}^{-}(\mathrm{p})$ is indicative of mixing down of $\mathrm{NO}_{3}^{-}$(p) in the RL (Watson and Chow, 2002; Pusede et al., 2016; Young et al., 2016), the current study provides an explicit, observationally constrained demonstration of this effect and highlights the dual roles of chemical production and advective loss in the RL.

The time-evolving relative contributions of surface-level $\mathrm{NO}_{3}^{-}(\mathrm{p})$ from the NBL, the RL and photochemical produc-

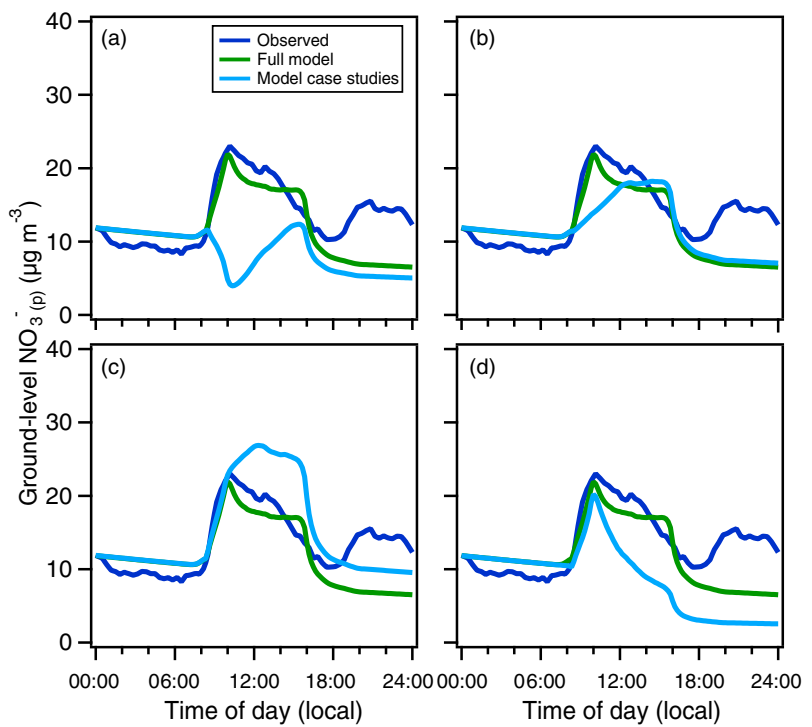

Figure 8. Model predictions of the diurnal variation in surface-level $\mathrm{NO}_{3}^{-}(\mathrm{p})$ under (a-c) different assumptions regarding the $\mathrm{NO}_{3}^{-}(\mathrm{p})$ concentration and vertical variability in the early-morning RL or (d) without daytime photochemical production of $\mathrm{NO}_{3}^{-}(\mathrm{p})$. In all panels the blue curve shows the observations and the green curve shows the full observationally constrained model results (identical to Fig. 6) for the average of the 4 flight days in Episode 1. For (ac), the assumptions were as follows: (a) the $\left[\mathrm{NO}_{3}^{-}(\mathrm{p})\right]_{\mathrm{RL}}$ is equal to zero; (b) the $\left[\mathrm{NO}_{3}^{-}(\mathrm{p})\right]_{\mathrm{RL}}$ is constant with altitude and equal to the $\mathrm{NO}_{3}^{-}(\mathrm{g}+\mathrm{p})$ at 15:00 LT in the previous afternoon, corresponding to a case of zero net production or loss; (c) the $\left[\mathrm{NO}_{3}^{-}(\mathrm{p})\right]_{R L}$ is constant with altitude and equal to the maximum observed $\left[\mathrm{NO}_{3}^{-}(\mathrm{p})\right]$ in the early-morning RL profile.

tion are individually quantifiable from the model for this episode (Fig. 7b). As the ML rises, the relative contribution of $\mathrm{NO}_{3}^{-}(\mathrm{p})$ from the $\mathrm{RL}$ rapidly increases, reaching $\sim 80 \%$ at the 10:00-11:00 LT peak. After this point, the relative contribution of $\mathrm{NO}_{3}^{-}$(p) from photochemical production increases continuously. By the time that decoupling of the NBL occurs $\left(\sim\right.$ 15:00 LT), photochemically produced $\mathrm{NO}_{3}^{-}(\mathrm{p})$ comprises $58 \%$ of surface-level $\mathrm{NO}_{3}^{-}(\mathrm{p})$ while $\mathrm{NO}_{3}^{-}(\mathrm{p})$ from the previous nights' RL still comprises $40 \%$; the contribution of $\mathrm{NO}_{3}^{-}$(p) that was in the NBL is negligible $(<2 \%)$. Pusede et al. (2016) showed that future decreases in $\mathrm{NO}_{x}$ emissions are more likely to decrease nighttime than daytime $\mathrm{NO}_{3}^{-}(\mathrm{p})$ production. The results here therefore suggest that decreases in $\mathrm{NO}_{3}^{-}$(p) may be more apparent, on average, in the morning than the afternoon since the fractional contributions of nighttime-produced versus daytime-produced $\mathrm{NO}_{3}^{-}(\mathrm{p})$ shift throughout the day. However, care must be taken when interpreting observations from individual days since the meteorological conditions that favor observation of an earlymorning increase will not always occur (discussed further below). Since it is assumed here that $\mathrm{OH}$ scales with solar 
radiation, the potential for enhanced production of $\mathrm{OH}$ (and subsequently $\mathrm{NO}_{3}^{-}(\mathrm{p})$ ) in the early morning via, for example, HONO photolysis is not accounted for in the model (Pusede et al., 2016). If this process were included, the increase in morning surface-level $\mathrm{NO}_{3}^{-}$(p) would be even greater than is already calculated from mixing down of $\mathrm{NO}_{3}^{-}(\mathrm{p})$ in the RL. Since the observationally constrained model already predicts a somewhat larger peak at 10:00 LT for surface-level $\mathrm{NO}_{3}^{-}$(p) concentrations compared to the observations, earlymorning photochemical production appears to have had a relatively limited influence on the morning surface-level $\mathrm{NO}_{3}^{-}(\mathrm{p})$ compared to mixing down of nocturnal $\mathrm{NO}_{3}^{-}(\mathrm{p})$ during this episode.

While vertical mixing and the shape of the $\mathrm{NO}_{3}^{-}(\mathrm{p})$ vertical profile are what predominately drive the morning temporal evolution in the surface-level $\mathrm{NO}_{3}^{-}(\mathrm{p})$ (especially the peak) for this episode, the afternoon behavior, especially between $\sim$ 13:00 and 16:00 LT, is shaped by the balance between photochemical production and loss via (i) dilution by entrainment of FT air and (ii) evaporation of $\mathrm{NO}_{3}^{-}$(p) and subsequent dry deposition of $\mathrm{HNO}_{3}$ gas, i.e., a gas-phase pump for $\mathrm{NO}_{3}^{-}$(p) loss. Here, the relative importance of these loss pathways is considered. The latter process (gas-phase pump) has been previously considered by Pusede et al. (2016) while the former (FT entrainment) was not. Loss through dry deposition of $\mathrm{NO}_{3}^{-}(\mathrm{p})$ is negligible since deposition velocities for $\mathrm{HNO}_{3}\left(v_{\mathrm{d}}=1-10 \mathrm{~cm} \mathrm{~s}^{-1}\right)$ are much larger than for particles $\left(v_{\mathrm{d}}=0.001-0.1 \mathrm{~cm} \mathrm{~s}^{-1}\right)$ (Meyers et al., 1989; Horii et al., 2005; Farmer et al., 2013; Pusede et al., 2016). These loss mechanisms ultimately limit the extent of the pollution episode buildup. Once the daytime model ML reaches maximum height, entrainment into the ML of typically cleaner air from just above the ML (i.e., from the FT) occurs. The timeevolving entrainment rates are estimated from the CLASS model (Appendix C).

Considering the gas-phase pump, the warm (typically $290 \mathrm{~K})$ and dry ( $\mathrm{RH}=40 \%$ or less during the campaign) afternoon conditions enhance evaporation of $\mathrm{NO}_{3}^{-}(\mathrm{p})$ relative to nighttime and early-morning conditions, thereby increasing loss through dry deposition of $\mathrm{HNO}_{3}$ gas in the afternoon (Pusede et al., 2016). However, total ammonia is in substantial excess (3.8-8.9 times $\mathrm{NO}_{3}^{-}(\mathrm{g}+\mathrm{p})$ on a molar basis), with thermodynamic calculations indicating that the gasphase fraction of $\mathrm{NO}_{3}^{-}$is $<0.15$ during the daytime and near zero at night when it is colder and RH is higher (Fig. 3). These estimates of the gas-phase fraction of $\mathrm{NO}_{3}^{-}$are similar to the observational measurements of Parworth et al. (2017), who determined the daytime and nighttime averages during the first episode were $0.08 \pm 0.03(1 \sigma)$ and $0.04 \pm 0.05(1 \sigma)$, respectively. Importantly, the gas-phase fraction here is substantially smaller than that estimated in Pusede et al. (2016), who found a daytime gas-phase fraction of 0.4 (median) and a $24 \mathrm{~h}$ average of 0.15 . Consequently, the loss of nitrate via the gas-phase pump is less than in their analysis and suggests that the role of this pathway was likely overestimated.
The general influence of the gas-phase fraction on loss via dry deposition is shown in Fig. S11. In general, the results indicate that the gas-phase fraction has a strong influence on the loss of $\mathrm{NO}_{3}^{-}$(p) due to $\mathrm{HNO}_{3}$ deposition.

Including both FT entrainment and dry deposition, the box model reasonably reproduces the observed afternoon decrease in surface-level $\mathrm{NO}_{3}^{-}$(p). This allows assessment of the relative importance of these two loss processes by turning them off one at a time (Fig. 7c). The calculations indicate that entrainment of clean FT air plays an important role in the afternoon surface concentration decline. Without entrainment, the model predicts that the afternoon $\mathrm{NO}_{3}^{-}(\mathrm{p})$ would be $\sim 18 \%$ higher, leading to a double-humped daytime profile. Despite the relatively low gas-phase fraction, the gas-phase pump also contributes to the afternoon decline. The model results indicate that these two loss processes contribute approximately equally to the afternoon decline. There are, however, a few hours when the gas-phase pump is potentially of extreme importance. When the RL decouples and the surface mixed layer becomes quite shallow the rate of loss due to dry deposition is enhanced. This leads to a rapid decrease in surface-level $\mathrm{NO}_{3}^{-}$(p). Yet, the concurrent decrease in the NBL temperature and increase in $\mathrm{RH}$ and $\mathrm{NH}_{3}$ enhances the partitioning of nitrate to the particle phase, thereby limiting the impact of this rapid decline over time. (In the model here, the decoupling is assumed to occur very rapidly while the temperature and RH changes are from observations and occur more gradually. If the decoupling were actually slower the influence of the gas-phase pump at this point in time would be reduced and the modeled decrease in $\mathrm{NO}_{3}^{-}(\mathrm{p})$ that occurs around 15:00-17:00 LT would be less than shown.)

The model predicts that after decoupling and cooling occur the surface-level $\mathrm{NO}_{3}^{-}$(p) will continue to decrease at $\sim 2 \% \mathrm{~h}^{-1}$ overnight via the gas-phase pump, which is similar to the loss rate observed between midnight and 07:00 LT (Fig. 7a). If the gas-phase pump is turned off completely (i.e., the nitric acid deposition velocity is set to zero), there is an increase in the modeled $\mathrm{NO}_{3}^{-}(\mathrm{p})$ that begins at $\sim$ 15:00 LT (when decoupling occurs) and continues until 18:00 LT (Fig. 7c). This is a result of the continual decrease in temperature and increase in $\mathrm{RH}$ enhancing partitioning to the particle phase. Although not a focus of this study, on some days, there is a sharp increase in surface-level $\mathrm{NO}_{3}^{-}(\mathrm{p})$ observed in the evening, starting around 20:00 LT. While this could theoretically result from enhanced partitioning to the particle phase at night, the timing does not match the observed temperature and RH variations. Surface-level chemical production of nitrate via $\mathrm{N}_{2} \mathrm{O}_{5}$ hydrolysis could alternatively be the source of this increase, but given the near-zero surface-level $\mathrm{O}_{3}$ concentration due to titration by NO the production via this pathway would be insufficient. This evening increase is observed on many days, although with somewhat variable timing and magnitude (Fig. S8). Thus, it may be that the evening increase results from advection to the measurement site of air from a not-too-distant location (given low 
wind speeds) that has higher surface concentrations. Regardless, while the reason for this nighttime increase in surface $\mathrm{NO}_{3}^{-}$(p) remains unclear, the occurrence does not impact the analysis of the early-morning and daytime $\mathrm{NO}_{3}^{-}$(p) behavior.

The cumulative impact of the nocturnal production in the $\mathrm{RL}$, daytime photochemical production and afternoon loss processes is that the $\mathrm{NO}_{3}^{-}$(p) concentration at $\sim 15: 00 \mathrm{LT}$, the point when decoupling of the RL occurs, is slightly higher than that at 08:00 LT during the episode. Therefore, there is a gradual net increase (average of $1.32 \mu \mathrm{g} \mathrm{m}^{-3} \mathrm{day}^{-1}$ ) in surface-level $\mathrm{NO}_{3}^{-}(\mathrm{p})$ as the episode progresses, albeit with day-to-day variability (Fig. 6b). For comparison, the $24 \mathrm{~h}$ average-surface-level $\mathrm{NO}_{3}^{-}(\mathrm{p})$ increases by $0.66 \mu \mathrm{g} \mathrm{m}^{-3} \mathrm{day}^{-1}$. While decreasing $\mathrm{NO}_{x}$ emissions and $\mathrm{NO}_{3}^{-}$(p) production, especially nocturnal production (Pusede et al., 2016), is the most direct and reliable route towards decreasing surface $\mathrm{NO}_{3}^{-}(\mathrm{p})$ concentrations (Kleeman et al., 2005), decreases in $\mathrm{NH}_{3}$ could theoretically also have some influence on $\mathrm{NO}_{3}^{-}$(p) by increasing the efficiency of the gas-phase pump. However, this will only be the case if $\mathrm{NH}_{3}$ decreases exceed decreases in $\mathrm{NO}_{x}$ by at least a factor of 5 such that the ratio between the two is changed substantially and the gas-phase fraction is increased (Fig. 3). Such preferential targeting of $\mathrm{NH}_{3}$ sources is therefore highly unlikely to be an efficient control strategy, at least for the SJV where the total ammonia-to-nitrate ratio is large. In regions where the $\mathrm{NH}_{4}^{+}(\mathrm{g}+\mathrm{p}): \mathrm{NO}_{3}^{-}(\mathrm{g}+\mathrm{p})$ molar ratio is closer to unity, the nitrate partitioning is more sensitive to changes in this ratio and thus ammonia control could potentially prove effective.

\subsection{Comparison between episodes}

The above analysis focuses on observations made during one pollution episode, but there was a second pollution episode observed during DISCOVER-AQ (30 January-5 February 2013). The episode-averaged diurnal behavior of the surface $\mathrm{NO}_{3}^{-}(\mathrm{p})$ concentration for this second episode showed evidence of an early-morning increase, but the increase is not as sharp as the first episode (Fig. 9). Additionally, the dayto-day variability in the surface $\mathrm{NO}_{3}^{-}$(p) was much greater during the second episode; on some days, there was minimal evidence of an early-morning increase but on others there was a substantial increase. The shapes of the early-morning vertical $\mathrm{NO}_{3}^{-}$(p) profiles (around 09:30 LT) were notably different during Episode 2 on 2 of the flight days as well, as was the evolution of the profiles from morning to afternoon (Fig. S12). The afternoon mixed layer heights were much higher during Episode 2 than Episode 1, ranging from 600 to $700 \mathrm{~m}$ a.g.l. compared to $300-400 \mathrm{~m}$ a.g.l., respectively. The early-morning mixed layer heights were also higher during Episode $2(\sim 170 \mathrm{~m})$ compared to Episode 1 (around $70 \mathrm{~m}$ ). During Episode 1, the surface-level winds exhibit a consistent shift in direction from easterly in the early morning (05:00-08:00 LT) to southerly in the later morning (09:0012:00 LT), and the mean surface-level wind speed increased over this same period, from 0.31 to $0.82 \mathrm{~m} \mathrm{~s}^{-1}$ (Fig. 9). In contrast, during Episode 2 there was a lack of day-to-day consistency in the surface wind direction, especially during the early morning (05:00-08:00 LT), and there was a more substantial change in the mean surface-level wind speed from the early morning to later morning, from 0.32 to $1.12 \mathrm{~m} \mathrm{~s}^{-1}$ (Fig. 9). The Episode 2 mean nighttime aloft wind speeds were also overall lower and more constant with altitude, with little variability from 150 to $400 \mathrm{~m}$. However, the wind speed did increase substantially from the surface to $150 \mathrm{~m}$ (Fig. S13). The aloft nocturnal winds during Episode 2 were somewhat more variable than Episode 1 winds in terms of the wind direction (Fig. 4 versus Fig. S13).

Overall, this increased day-to-day variability in both the surface $\mathrm{NO}_{3}^{-}$(p) and wind behavior, as well as a difference in the evolution of the $\mathrm{NO}_{3}^{-}$(p) vertical profiles from the early morning to late morning or early afternoon in Episode 2 compared to Episode 1, suggests that the meteorological conditions during the second episode were generally less conducive to simple interpretation using the mixing model discussed above. Instead, it seems that advection and export from the urban area were of increased importance during Episode 2, both overnight and especially in the earlyto-midmorning. The contrasting behavior between the two episodes suggests that while the observation of a sharp, earlymorning rise and peak in surface-level $\mathrm{NO}_{3}^{-}$(p) (such as during the first episode) might be generally considered a strong indicator of the production of $\mathrm{NO}_{3}^{-}(\mathrm{p})$ in the RL, the absence of such a feature does not preclude an important role for nocturnal production aloft.

\subsection{Linking to other regions}

Production of $\mathrm{NO}_{3}^{-}$(p) in the RL can vary widely based on initial concentrations of its precursor gases, as well as the rate of heterogeneous uptake of $\mathrm{N}_{2} \mathrm{O}_{5}$ by particles. It may be that production of $\mathrm{NO}_{3}^{-}$(p) via the $\mathrm{N}_{2} \mathrm{O}_{5}$ hydrolysis pathway may be significant in the aloft RL in other regions with similar geographical and meteorological conditions, such as Salt Lake Valley, Utah (Kuprov et al., 2014; Baasandorj et al., 2017). However, in valley regions with lower $\mathrm{NO}_{x}$ or $\mathrm{O}_{3}$ the nocturnal $\mathrm{PNO}_{3}^{-}$may be lower, thus limiting the importance of this pathway (Akira et al., 2005; Bigi et al., 2012). Among other factors, the extent to which nocturnal $\mathrm{NO}_{3}^{-}$(p) formation occurs more so in the surface layer versus in layers aloft will depend importantly on the extent of $\mathrm{NO}_{x}$ emissions at the surface (which titrate $\mathrm{O}_{3}$, suppressing particulate nitrate formation), the absolute and relative height of the nocturnal boundary layer (which affects the rate of $\mathrm{HNO}_{3}$ deposition and the air volumes in which nitrate production occurs), and gradients in $\mathrm{RH}, T$ and $\mathrm{NH}_{3}$ (Kim et al., 2014).

For example, Baasandorj et al. (2017) observe at their valley wall and valley floor sites in wintertime Utah that $\mathrm{O}_{3}$ concentrations near the surface remain well-above zero even during pollution episodes, thus allowing for surface-level 

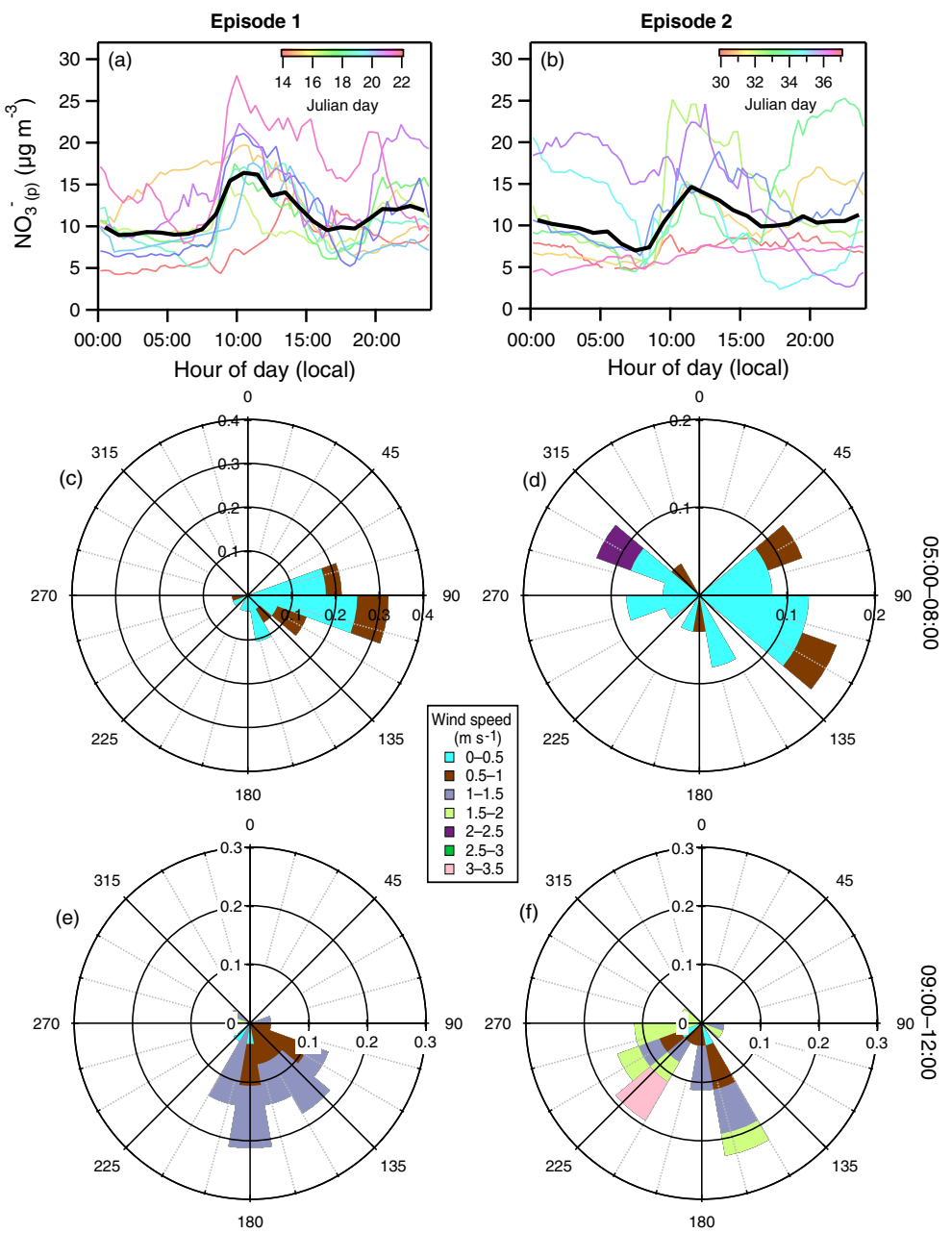

Figure 9. Panels $(\mathbf{a}, \mathbf{b})$ : diurnal variation in the surface-level particulate nitrate concentration during (a) the first episode and (b) the second episode. The solid black lines are the average profile over the episode and the colored lines are for individual days. Panels (c, d, e, f): wind roses for surface-level $(10 \mathrm{~m})$ winds in Fresno for the early morning (05:00-08:00 LT) during (c) Episode 1 and (d) Episode 2 and for the late morning (09:00-12:00 LT) during (e) Episode 1 and (f) Episode 2.

$\mathrm{NO}_{3}^{-}$(p) formation overnight, substantiated by direct measurements of $\mathrm{N}_{2} \mathrm{O}_{5}$, in addition to formation aloft. Nitratespecific diurnal profiles were not reported. In Shanghai, China, Wang et al. (2009) observed in fall 2007 that both $\mathrm{O}_{3}$ and $\mathrm{NO}_{2}$ remained elevated at night at the surface, with a concomitant increase in surface $\mathrm{NO}_{3}^{-}(\mathrm{p})$. And in wintertime Seoul, Korea, Kim et al. (2017) observed relatively limited diurnal variability in $\mathrm{O}_{3}$ and $\mathrm{NO}_{2}$ concentrations measured at $60 \mathrm{~m}$, with both remaining elevated throughout the night. However, they did not observe any notable buildup in $\mathrm{NO}_{3}^{-}(\mathrm{p})$ overnight, but did observe an $\mathrm{NO}_{3}^{-}(\mathrm{p})$ increase and peak in the morning, as here. In contrast, in Fresno the nighttime surface $\mathrm{O}_{3}$ levels during Episode 1 were nearly zero, suppressing surface $\mathrm{NO}_{3}^{-}$(p) formation. This near-zero nocturnal $\mathrm{O}_{3}$ is similar to observations by Kuprov et al. (2014) made a few years before Baasandorj et al. (2017) at one of the same valley floor sites in Utah, reflecting year-to-year differences.
Such differences can influence the extent to which a notable increase in $\mathrm{NO}_{3}^{-}(\mathrm{p})$ is observed to occur in the early morning as air is entrained from the residual layer to the surface. This is because if surface production and production in the residual layer are similar in magnitude the contrast between the two will be reduced and entrainment will appear to have a less apparent impact on the diurnal profile. However, because the effective volume of the residual layer is typically much larger than the nocturnal boundary layer (as is the case here), even without an observed increase in $\mathrm{NO}_{3}^{-}(\mathrm{p})$ at the surface in the morning the $\mathrm{NO}_{3}^{-}(p)$ produced in the residual layer can still dominate the overall $\mathrm{NO}_{3}^{-}$(p) burden during the day.

Additionally, comparison between the Baasandorj et al. (2017) observations of late-afternoon surface $\mathrm{NO}_{2}$ and $\mathrm{O}_{3}$ (which reflect the initial conditions within the residual layer) with the Fresno observations indicates that differences can 
exist in how nocturnal production in layers aloft influences the buildup and sustaining of $\mathrm{PM}_{2.5}$ in pollution episodes. They observed during a strong $\mathrm{PM}_{2.5}$ episode a slow buildup of $\mathrm{PM}_{2.5}$ followed by a plateau lasting multiple days. During this period, late-afternoon $\mathrm{O}_{3}$ concentrations decreased over time while late-afternoon $\mathrm{NO}_{2}$ was approximately constant (in the daily average). Consequently, the nitrate radical production rate in the residual layer, and thus the $\mathrm{N}_{2} \mathrm{O}_{5}$ and $\mathrm{NO}_{3}^{-}$(p) production rates, decreased over time in their study. In contrast, for Episode 1 here, the late-afternoon nitrate radical production rate increased over time across the episode (by $0.25 \mu \mathrm{g} \mathrm{m}^{-3} \mathrm{day}^{-1}$ ), with only a moderate decrease in the daytime $\mathrm{O}_{3}$ over time (Fig. S9). These differences reflect the different photochemical conditions between the regions and illustrate the coupling between the daytime photochemical conditions (i.e., $\mathrm{O}_{3}$ production) and nighttime $\mathrm{NO}_{3}^{-}$(p) formation above the surface.

\section{Conclusion}

This work combines surface and aircraft observations made during a pollution episode in 2013 to demonstrate that in the San Joaquin Valley (specifically Fresno, CA) production of $\mathrm{NO}_{3}^{-}(\mathrm{g}+\mathrm{p})$ in the nocturnal residual layer can play a crucial role in determining daytime surface concentrations of particulate $\mathrm{NO}_{3}^{-}$in winter, when photochemical production is relatively slow and morning boundary layers are extremely shallow. The influence of processes occurring in the aloft RL on $\mathrm{NO}_{3}^{-}$(p) surface concentrations is evident in the $\mathrm{NO}_{3}^{-}$(p) diurnal variability, specifically the occurrence of a midmorning peak in surface-level $\mathrm{NO}_{3}^{-}(\mathrm{p})$. While the midmorning peak has been previously suggested as a signature of nocturnal nitrate production aloft (Watson and Chow, 2002; Brown et al., 2006a; Lurmann et al., 2006; Pusede et al., 2016; Young et al., 2016), the current study makes novel use of vertical profiles of $\mathrm{NO}_{3}^{-}(\mathrm{p})$ concentrations measured multiple times on individual days to quantitatively illustrate the importance of nocturnal processes on surface concentrations. The analysis shows that the $\mathrm{NO}_{3}^{-}$(p) concentration in the morning-time mixed boundary layer can be dominated by nocturnally produced $\mathrm{NO}_{3}^{-}(\mathrm{p})$; vertical mixing in the early morning, which entrains air from the residual layer into the surface mixed layer, has a particularly large impact on the surface concentrations here due to the nocturnal boundary layer being exceptionally shallow. In the afternoon, photochemically produced nitrate contributes the majority of the total $\mathrm{NO}_{3}^{-}(\mathrm{p})$ burden for the episode examined but still with a substantial contribution from nocturnal production. The case study here illustrates that nocturnal $\mathrm{NO}_{3}^{-}$(p) production can play a critically important role in the buildup and sustaining of pollution episodes in the SJV, supporting previous suggestions made, in part, on the basis of calculated chemical production values and an assessment of multiyear trends in the relationship between $\mathrm{NO}_{3}^{-}$(p) and $\mathrm{NO}_{2}$ (Pusede et al., 2016).
The current work also demonstrates that a difference exists between the shape of the typical vertical profiles of $\mathrm{NO}_{3}^{-}(\mathrm{p})$ in the afternoon and early morning over Fresno. This difference is shown to very likely result from altitude-specific horizontal advection in the nocturnal RL leading to differential washout of $\mathrm{NO}_{3}^{-}(\mathrm{p})$ and precursor gases rather than from differences in chemical production rates. Consequently, there is a steep vertical gradient in $\mathrm{NO}_{3}^{-}$(p) in the early-morning $\mathrm{RL}$ that, in turn, influences the temporal evolution of surfacelevel $\mathrm{NO}_{3}^{-}(\mathrm{p})$ during the day, especially in the early morning. Ultimately, differential advection is shown to have an important role in limiting the maximum surface-level concentration of $\mathrm{NO}_{3}^{-}$(p) observed within the urban area during the day, which is a result of the urban-rural gradients being particularly steep (Pusede et al., 2016). Absent this overnight export of pollution from the city, nitrate pollution would build up during pollution events to a much greater extent. However, advection likely contributes to the buildup of $\mathrm{NO}_{3}^{-}$(p) throughout the valley, outside of the cities. Daytime loss processes are also shown to help in limiting the multiday buildup of surface-level $\mathrm{NO}_{3}^{-}(\mathrm{p})$. Afternoon entrainment of air from the cleaner free troposphere into the ML (and export of mixed layer air to the FT) is shown to be an important loss process for particulate nitrate. Janssen et al. (2012, 2013) have similarly identified afternoon loss via FT entrainment as an important process shaping the diurnal variability of surface-level organic aerosol concentrations in forested areas that are dominated by organic aerosol. Loss of $\mathrm{NO}_{3}^{-}(\mathrm{p})$ via dry deposition of $\mathrm{HNO}_{3}$ and subsequent evaporation of $\mathrm{NH}_{4} \mathrm{NO}_{3}$ is found to contribute to afternoon particulate nitrate loss, but the effect is limited by the (relatively) high afternoon boundary layer and the small gas-phase fraction of nitrate $(<0.15)$. However, this gas-phase pump may have a substantial influence on the surface concentrations in the few hours just after decoupling of the RL occurs, when the boundary layer height is low and it is still sufficiently warm. Consistent with previous suggestions (Kleeman et al., 2005; Pusede et al., 2016), we conclude that control strategies for the region should focus on the reduction of concentrations of $\mathrm{NO}_{x}$ and $\mathrm{O}_{3}$ (the latter of which might require VOC controls) in the midafternoon, specifically around the time that the RL decouples from the surface layer, as this largely determines the production rate of nitrate in the aloft RL.

Data availability. All data used in this study are available at the NASA DISCOVER-AQ website (https://doi.org/10.5067/Aircraft/DISCOVER-AQ/AerosolTraceGas). 


\section{Appendix A: Measurements}

\section{A1 Airborne measurements}

Airborne measurements used in this paper were made from the P3-B NASA aircraft during the DISCOVER-AQ field campaign in January-February 2013 in the San Joaquin Valley, California. All data are available from the publicly accessible DISCOVER-AQ website (NASA Atmospheric Science Data Center).

The P3-B was equipped with an array of instruments to measure both gas- and particle-phase properties. A TSI3563 nephelometer provided total scattering from dry particles at 450,550 and $700 \mathrm{~nm}$ and scattering at $550 \mathrm{~nm}$ by particles at $80 \%$ RH (Beyersdorf et al., 2016). Gas-phase $\mathrm{NH}_{3}$ was measured using a cavity ring-down spectroscopy with a Picarro G2103 (von Bobrutzki et al., 2010), using the NOAA aircraft $\mathrm{NH}_{3}$ inlet and calibration scheme as in Nowak et al. (2010). Measurements of $\mathrm{NO}, \mathrm{NO}_{2}, \mathrm{NO}_{x}$ and $\mathrm{O}_{3}$ were obtained through a four-channel chemiluminescence instrument (Brent et al., 2015). $\mathrm{CO}$ and $\mathrm{CH}_{4}$ were measured with a differential absorption $\mathrm{CO}$ measurement (DACOM) spectrometer (Sachse et al., 1987). Total gas $\left(\mathrm{HNO}_{3}\right)+$ particle $\left(\mathrm{NH}_{4} \mathrm{NO}_{3}\right)$ nitrate was measured using thermal-dissociation laser-induced fluorescence (TD-LIF), where $\mathrm{HNO}_{3}$ and volatilizable particulate nitrate are converted into $\mathrm{NO}_{2}$ for detection (Day et al., 2002). While the TD-LIF instrument is not optimized for particle sampling, most of the particulate mass was in the submicron size range, and thus inertial losses will likely only lead to a small (if any) negative bias in the measured particulate nitrate (Pusede et al., 2016). Aerosol size distributions for $0.06-1.0 \mu \mathrm{m}$ diameter particles were measured with an ultra-high sensitivity aerosol spectrometer (UHSAS). The UHSAS uses an optical sizing method but is calibrated relative to the mobility diameter. The P3-B flew throughout the SJV for 10 days and performed vertical spirals over six sites across the valley, including Fresno. The location of these sites and the flight path are shown in Fig. S2. This same flight path was repeated three times every day between approximately 08:30 and 15:00 LT, with vertical profiles over Fresno at approximately 09:3010:00 LT, 12:00-12:30 LT and 14:30-15:00 LT. This enables assessment of the evolution of the species-specific vertical profile during the day across the valley. Out of the 10 research flights during the campaign, only 8 of them have been used here due to gaps in the dataset. Four of these days are during the first pollution episode (18, 20, 21 and 22 January) and 4 are during the second pollution episode (30 and 31 January, and 1 and 4 February).

Observations of the light scattering coefficient at $550 \mathrm{~nm}$ $\left(\sigma_{\text {sca }}\right)$ for dry and humidified particles (no size cutoff) made from the P3-B (Beyersdorf et al., 2016) have been used to estimate the vertical distribution of PM mass and $\mathrm{NO}_{3}^{-}(\mathrm{p})$ concentrations. Scattering is linearly related to the total mass concentration of PM. The observed hygroscopicity is depen-
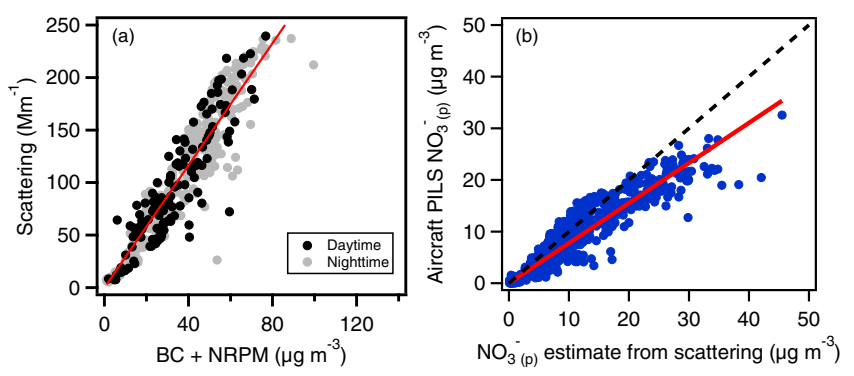

Figure A1. (a) Total particle scattering at $550 \mathrm{~nm}\left(\mathrm{Mm}^{-1}\right)$ versus $\mathrm{PM}_{1.0}$ mass (submicron black carbon $(\mathrm{BC})+$ non-refractory $\mathrm{PM}_{1.0}\left(\mathrm{NR}-\mathrm{PM}_{1}\right)$ ) concentration $\left(\mu \mathrm{g} \mathrm{m}^{-3}\right)$ observed at ground level in Fresno. The solid red line is the orthogonal distance regression fit including data only during the daytime (black circles) between 08:00 LT and 16:00 LT; slope $=2.83 \mathrm{~mm}^{2} \mu \mathrm{g}^{-1}$. (b) $\mathrm{NO}_{3}^{-}$(p) concentration measured by PILS on P3-B aircraft versus that estimated from scattering using the relation $\mathrm{NO}_{3}^{-}(\mathrm{p})=\gamma \cdot \sigma_{\text {sca, dry }} / 2.83$. The solid red line is the linear fit to the data, with slope $=0.78$. The dashed black line is the $1: 1$ line.

dent on particle composition, with higher hygroscopicity indicative of a higher particulate inorganic fraction and lower hygroscopicity indicative of a higher particulate organic fraction; the relationship between hygroscopicity and the inorganic fraction (or the organic fraction) is reasonably linear when the inorganic species are primarily ammonium sulfate and ammonium nitrate (Zhang et al., 2014), as these have similar hygroscopicities (Petters and Kreidenweis, 2007). The particulate nitrate concentration is much larger than the particulate sulfate concentration, as determined from both the surface and aircraft measurements $(<600 \mathrm{~m}$ a.g.l.), with nitrate-to-sulfate mass ratios of 8 and 16, respectively (both determined from PILS measurements). Thus, the observed hygroscopicity is primarily reflective of the particulate nitrate fraction (Parworth et al., 2017). More specifically, a linear relationship was observed between surface-level measurements of dry $\sigma_{\text {scat }}$ and $\mathrm{PM}_{1.0}$ (black carbon $(\mathrm{BC})+$ nonrefractory $\mathrm{PM}_{1.0}$ ) mass concentrations in Fresno (slope = $2.83 \mathrm{~m}^{2} \mathrm{~g}^{-1}$, with intercept forced through zero; Fig. A1a). Only data points between 08:00 LT and 16:00 LT were included in determining this relationship to reflect the time period during which the airborne measurements were obtained. The observed relationship for dry, surface-level $\sigma_{\text {sca }}$ and NR$\mathrm{PM}_{1}$ is used to estimate the NR-PM 1 concentration during the vertical profiles from the aircraft dry $\sigma_{\text {scat }}$ measurements. The hygroscopicity (water uptake) of a particle depends on its chemical composition. Inorganic components, predominantly $\mathrm{NO}_{3}^{-}$and ammonium in the wintertime SJV region (Young et al., 2016) are highly hygroscopic while organic components of $\mathrm{PM}_{1}$ tend to have much lower hygroscopicity (Petters and Kreidenweis, 2007). Thus, measurements of the particle hygroscopicity can be used to estimate the ratio of inorganic to organic mass in the sampled PM (Massoli et al., 2009; Parworth et al., 2017). The average particle hy- 
Table A1. Summary of instruments deployed and measurements on ground and on aircraft made during the DISCOVER-AQ campaign.

\begin{tabular}{|c|c|c|c|c|}
\hline Platform & Measurement & Instrument & Uncertainty & $\begin{array}{r}\text { Response } \\
\text { time }\end{array}$ \\
\hline $\begin{array}{l}\text { NASA P3-B aircraft } \\
+ \text { ground }\end{array}$ & $\begin{array}{l}\text { Total and submicron scattering } \\
\text { at } 450,550 \text { and } 700 \mathrm{~nm}\end{array}$ & $\begin{array}{l}\text { Integrating nephelometer } \\
\text { (TSI 3563) }\end{array}$ & $5 \%$ & $1 \mathrm{~s}$ \\
\hline NASA P3-B Aircraft & Nitrate (gas + particle) & $\begin{array}{l}\text { Thermal-dissociation laser-induced } \\
\text { fluorescence (TD-LIF) }\end{array}$ & $15 \%$ & $1 \mathrm{~s}$ \\
\hline NASA P3-B Aircraft & $\begin{array}{l}\text { Carbon monoxide }(\mathrm{CO}) \text {, } \\
\text { methane }\left(\mathrm{CH}_{4}\right)\end{array}$ & $\begin{array}{l}\text { Differential absorption } \\
\text { CO measurement (DACOM) }\end{array}$ & $<2 \%$ & $1 \mathrm{~s}$ \\
\hline NASA P3-B Aircraft & $\begin{array}{l}\text { Nitrogen monoxide }(\mathrm{NO}) \text {, } \\
\text { nitrogen dioxide }\left(\mathrm{NO}_{2}\right) \\
\text { and ozone }\left(\mathrm{O}_{3}\right)\end{array}$ & Four-channel chemiluminescence & $\begin{array}{l}10 \% \text { for } \mathrm{NO}, \\
15 \% \text { for } \mathrm{NO}_{2}, \\
\text { and } 5 \% \text { for } \mathrm{O}_{3}\end{array}$ & $1-3 \mathrm{~s}$ \\
\hline NASA P3-B Aircraft & Ammonia $\left(\mathrm{NH}_{3}\right)$ & Picarro G2103 & $35 \%$ & $10 \mathrm{~s}$ \\
\hline NASA P3-B Aircraft & $\begin{array}{l}\text { Aerosol size distribution } \\
(0.06-1 \mu \mathrm{m})\end{array}$ & $\begin{array}{l}\text { Ultra-high sensitivity aerosol } \\
\text { spectrometer (UHSAS) }\end{array}$ & $20 \%$ & $1 \mathrm{~s}$ \\
\hline NASA P3-B Aircraft & $\begin{array}{l}\text { Meteorological and navigational } \\
\text { measurements onboard }\end{array}$ & $\begin{array}{l}\text { P3-B Project Data } \\
\text { System (PDS) }\end{array}$ & - & $1 \mathrm{~s}$ \\
\hline Ground & $\mathrm{PM}_{2.5}$ mass concentration & Beta attenuation monitor (BAM) & $16 \%$ & $1 \mathrm{~h}$ \\
\hline Ground & $\mathrm{NO}, \mathrm{NO}_{2}$ & Chemiluminescence & $20 \%$ & $1 \mathrm{~h}$ \\
\hline Ground & $\mathrm{O}_{3}$ & NIST Standard Reference Photometer (SRP) & $2 \%$ & $1 \mathrm{~h}$ \\
\hline Ground & Speciated non-refractory $\mathrm{PM}_{1.0}$ & $\begin{array}{l}\text { High-Resolution Time-of-Flight Aerosol } \\
\text { Mass Spectrometer (HR-ToF-AMS) }\end{array}$ & $25 \%$ & $5 \mathrm{~min}$ \\
\hline Ground & $\begin{array}{l}\text { Water-soluble components } \\
\text { of } \mathrm{PM}_{2.5}\end{array}$ & $\begin{array}{l}\text { Particle-into-liquid sampler (PILS) coupled } \\
\text { with two ion chromatography systems }\end{array}$ & $10-20 \%$ & $20 \mathrm{~min}$ \\
\hline Ground & Aerosol particle size & Scanning mobility particle sizer & $10 \%$ & $1 \mathrm{~min}$ \\
\hline Ground & Aerosol particle size & Aerodynamic particle sizer & $20 \%$ & $1 \mathrm{~s}$ \\
\hline Ground & $\begin{array}{l}\text { Refractive black carbon } \\
\text { mass concentration }\end{array}$ & $\begin{array}{l}\text { DMT Single Particle Soot } \\
\text { Photometer (SP2) }\end{array}$ & $30 \%$ & $5 \mathrm{~min}$ \\
\hline Ground & $\begin{array}{l}\text { Relative humidity } \\
\text { and temperature }\end{array}$ & & $\begin{array}{r}\mathrm{RH}: \pm 2 \% \\
T: \pm 0.1 \mathrm{~K}\end{array}$ & $1 \mathrm{~h}$ \\
\hline
\end{tabular}

groscopicity was characterized by the optical hygroscopicity parameter, $\gamma$, defined by Eq. (A1).

$\gamma=\frac{\ln \left[\frac{\sigma_{\text {sca, wet }}}{\sigma_{\text {sca, dry }}}\right]}{\ln \left[\frac{100-\mathrm{RH}_{\mathrm{dry}}}{100-\mathrm{RH}_{\mathrm{wet}}}\right]}$,

where $\sigma_{\text {scat, wet }}$ and $\sigma_{\text {scat, dry }}$ are the scattering coefficients (in $\left.\mathrm{Mm}^{-1}\right)$ measured under wet $\left(\mathrm{RH}_{\mathrm{wet}}=80 \%\right.$ ) and dry $\left(\mathrm{RH}_{\mathrm{dry}}=20 \%\right)$ conditions, respectively. The parameter $\gamma$ varies reasonably linearly with the particle inorganic mass fraction (Massoli et al., 2009). Therefore, an initial estimate of $\mathrm{NO}_{3}^{-}$(p) concentrations at high time resolution, and thus as a function of altitude, is obtained from the equation $\left[\mathrm{NO}_{3}^{-}(\mathrm{p})=\gamma \cdot \sigma_{\mathrm{sca}}\right.$, dry $/ 2.83$. The factor of 2.83 has units of $\mathrm{m}^{2} \mathrm{~g}^{-1}$ and comes from the $\sigma_{\text {scat }}$ versus NR-PM 1 relationship determined above. However, previous studies show some variability in the linear relationship between $\gamma$ and inorganic mass fraction and, importantly, typically have slopes somewhat less than unity and nonzero intercepts, as is assumed in the above conversion (e.g., Massoli et al., 2009). Therefore, the low-time-resolution aircraft PILS $\mathrm{NO}_{3}^{-}(\mathrm{p})$ measurements (which are not appropriate for vertical profiles) were used to calibrate the above high-time-resolution $\mathrm{NO}_{3}^{-}$(p) estimates. There was a strong, linear correlation between the $\mathrm{NO}_{3}^{-}$(p) observed by the PILS and the initially estimated $\mathrm{NO}_{3}^{-}$(p) (Fig. A1b). This demonstrates the general validity of the estimation approach. However, the PILS NO $\mathrm{N}_{3}^{-}(\mathrm{p})$ concentrations were, on average, $22 \%$ lower than the initially estimated $\mathrm{NO}_{3}^{-}(\mathrm{p})$. Therefore, the initially estimated $\mathrm{NO}_{3}^{-}(\mathrm{p})$ concentrations were adjusted downwards by $22 \%$, and the final expression relating $\sigma_{\text {sca, dry }}\left(\right.$ in $\mathrm{Mm}^{-1}$ ) and $\gamma$ to $\mathrm{NO}_{3}^{-}$(p) concentrations (in $\mu \mathrm{g} \mathrm{m}^{-3}$ ) is

$\left[\mathrm{NO}_{3}^{-}(p)\right]=\frac{\gamma \cdot \sigma_{\text {sca, dry }}}{3.63}$.

The uncertainty in the estimated $\left[\mathrm{NO}_{3}^{-}(\mathrm{p})\right]$ is approximately $20 \%$, based on the scatter around the best-fit line in Fig. A1. 


\section{A2 Ground measurements}

Fresno $\left(36.745^{\circ} \mathrm{N}, 119.77^{\circ} \mathrm{W}\right)$ was a "supersite" where comprehensive, continuous measurements of the chemical and physical properties of particulate matter were made. Chemical composition of non-refractory $\mathrm{PM}_{1.0}$ was measured by a High-Resolution Time-of-Flight Aerosol Mass Spectrometer (HR-ToF-AMS) (Young et al., 2016). The soluble fraction of $\mathrm{PM}_{3.0}$ was characterized using a particle-intoliquid sampler coupled to an ion chromatograph (Parworth et al., 2017). Gas-phase water-soluble species were collected at 5-7 $\mathrm{h}$ time resolution using an automatic-switching annular denuder system placed in front of the PILS and were analyzed offline with ion chromatography after extraction (Parworth et al., 2017). The combination of the denuder measurements and the particle measurements allowed for the determination of the gas-phase fraction of nitrate. Light extinction and light absorption coefficients were measured using the University of California (UC) Davis cavity ring-down photoacoustic spectrometer, and scattering coefficients were determined by the difference (Cappa et al., 2012; Lack et al., 2012). Refractory black carbon concentrations were measured using a single particle soot photometer (Schwarz et al., 2006). In situ gas-phase measurements of $\mathrm{NO}, \mathrm{NO}_{2}$ and $\mathrm{O}_{3}$, along with environmental factors ( $T$ and $\mathrm{RH}$ ) were made by the California Air Resources Board. Particle size distributions were measured using a scanning mobility particle sizer (size range: $10-800 \mathrm{~nm}$ ) and an aerodynamic particle sizer (700 nm-6 $\mu \mathrm{m}$ ). Measurements included in the current study are listed in Table A1.

Additionally, a radiosonde was used to obtain vertical profiles of pressure, temperature and humidity over nearby Huron $\left(36.203^{\circ} \mathrm{N}, 120.103^{\circ} \mathrm{W}\right)$ twice a day - once in the morning around 08:00 LT and again in the evening at 16:00 LT. Diurnal measurements of the surface heat flux and friction velocity were determined from measurements made with a sonic anemometer at Huron. Measurements of wind speed and wind direction as a function of altitude at nearby Visalia, CA, are from the National Oceanic and Atmospheric Administration (NOAA) Profiler Network (https://www.esrl.noaa.gov/psd/data/obs/ instruments/WindProfilerDescription.html).

\section{Appendix B: Determining mixed boundary layer height}

The mixed layer (ML) heights have been determined from each of the vertical profiles of potential temperature $(\theta)$, relative humidity, $\mathrm{CO}$ and $\mathrm{CH}_{4}$ measured from the $\mathrm{P} 3-\mathrm{B}$ aircraft. Example profiles for each of the three flight legs on 18 January 2013 are shown in Fig. B1. The altitude at which there is a strong change in the slope, from being approximately altitude independent to having a steep gradient, is determined to be the top of the ML. The vertical profile measurements allow for the determination of the ML height over Fresno

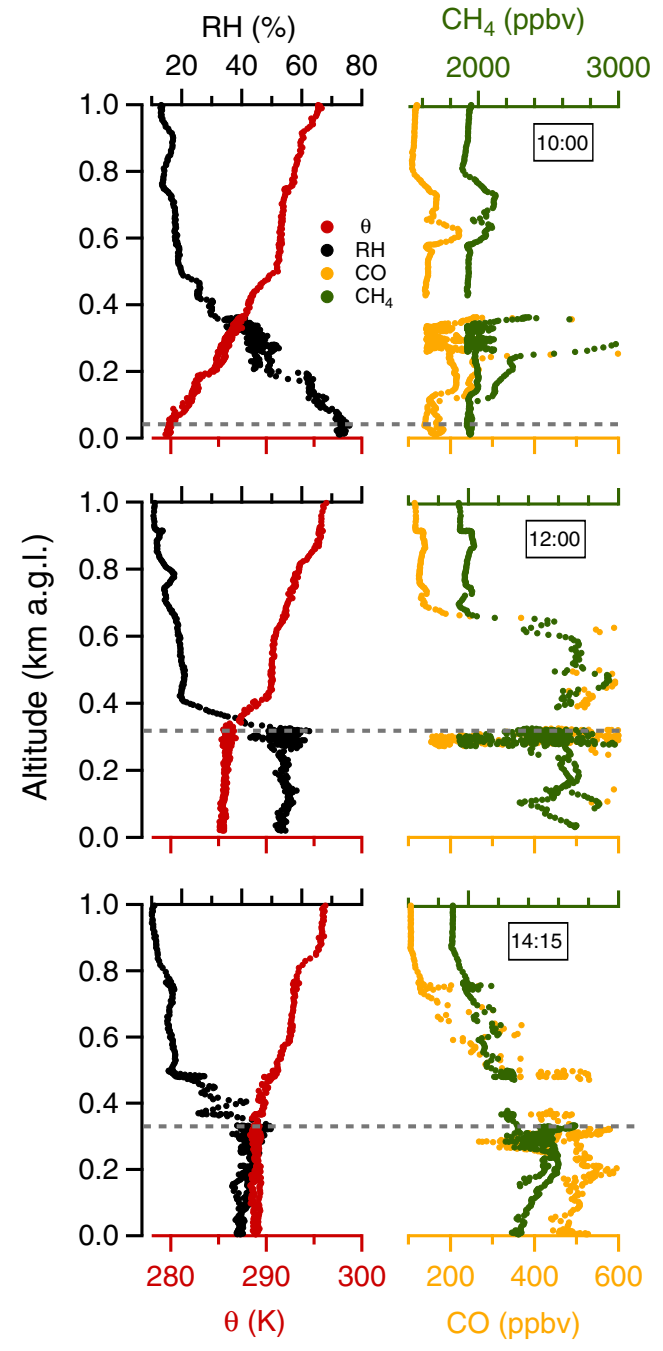

Figure B1. Vertical profiles of potential temperature, $\theta(\mathrm{K})$; relative humidity, RH (\%); mixing ratios of carbon monoxide, $\mathrm{CO}$ (ppbv); and methane, $\mathrm{CH}_{4}$ (ppbv), measured from the P3-B aircraft over Fresno on 18 January 2013. The horizontal dashed gray line indicates the mixed boundary layer heights.

around 10:00 LT, 12:30LT and 14:30LT. The ML height at 08:00 LT is separately determined from the radiosonde measurements at nearby Huron (located $83 \mathrm{~km} \mathrm{SSW}$ ), as the flight data do not allow for the characterization of ML height this early. It is assumed that the 08:00 LT ML measurements at Huron are representative of the ML heights in Fresno. The observed ML height increases with time from 08:00 LT until approximately noon or 13:00 LT, after which it is approximately constant. The rise in ML height with time is modeled using the Chemistry Land-surface Atmosphere Soil Slab model (Vilà-Guerau De Arellano et al., 2015). The CLASS model allows for the estimation of ML heights with finer time resolution than the observations (i.e., in between flights; shown as black dots in Fig. B2) and of the corresponding time-dependent entrainment velocities. The model input pa- 


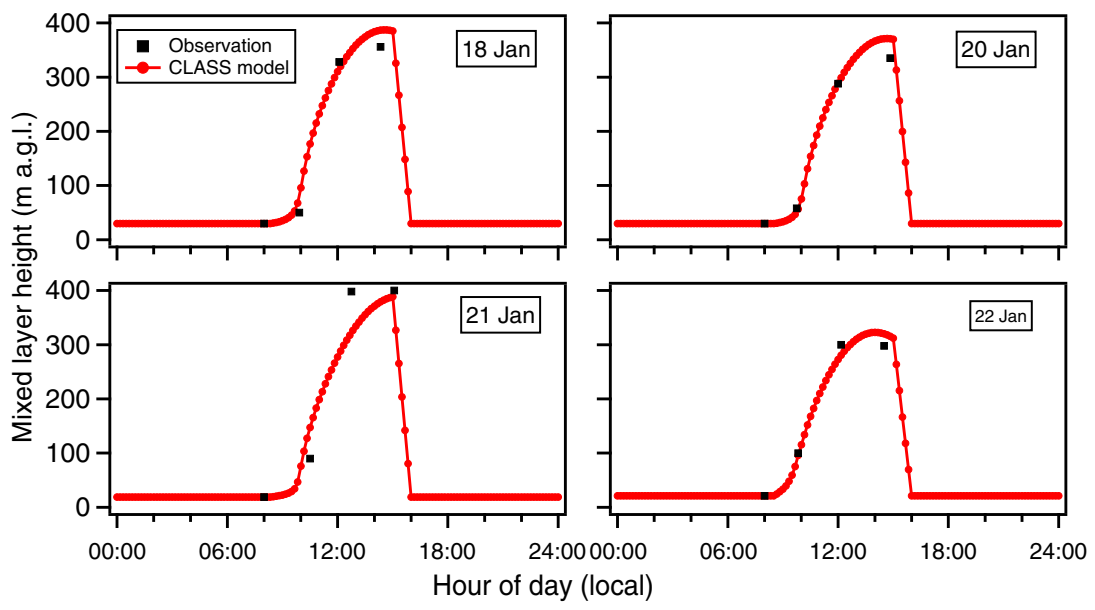

Figure B2. Evolution of the ML height with time (starting at 08:00 LT) on the 4 flight days in Episode 1. The observational constraints are shown as black circles, where the first point comes from nearby balloon sonde measurements and the last three from the P3-B vertical profiles.

rameters are constrained by observations from nearby Huron of the nocturnal boundary layer height, the morning inversion strength $(\sim 08: 00 \mathrm{LT})$, the sensible surface heat flux, the friction velocity and the lapse rate through the residual layer, as well as by an estimate of the subsidence rate based on Trousdell et al. (2016). The model inputs are adjusted to ensure that the modeled ML growth agrees reasonably well with the observations from the P3-B over Fresno (Fig. B2). The resulting average entrainment velocities in the afternoon (13:00-16:00 LT) from the CLASS model agree well with independently determined entrainment rates based on afternoon decline in $\mathrm{SO}_{4}^{2-}$ (p) for the Episode 1 days. Since $\mathrm{SO}_{4}^{2-}$ (p) is effectively nonvolatile and since photochemical production via oxidation of $\mathrm{SO}_{2}$ is relatively slow, the decline in $\mathrm{SO}_{4}^{2-}(\mathrm{p})$ in the afternoon can be attributed solely to the dilution from entrainment of "clean" FT air since the influence of the gas-phase pump is small. After 15:00 LT the boundary layer is assumed to linearly drop over a $1 \mathrm{~h}$ period to the NBL height observed at 08:00 LT the same day. A relatively rapid $(\sim 1 \mathrm{~h})$ decline in the mixed layer height is consistent with wintertime observations of diurnal BLH profiles (Bianco et al., 2011).

The sensitivity of the box model to the boundary layer growth predicted by the (observationally constrained) CLASS model has been examined. An alternative boundary layer growth profile was estimated by fitting the observed P3-B ML heights using a sigmoidal function (Fig. B3). The general shapes of the CLASS and sigmoidal profiles are similar, although the sigmoidal profile exhibits a somewhat faster rise. Entrainment of FT air in the afternoon for the sigmoidal growth profile was accounted for using the average entrainment rates estimated from the observed $\mathrm{SO}_{4}^{2-}(\mathrm{p})$ loss rates and assuming that entrainment begins at noon, when the BLH was near the maximum. The same linear decrease in the BLH

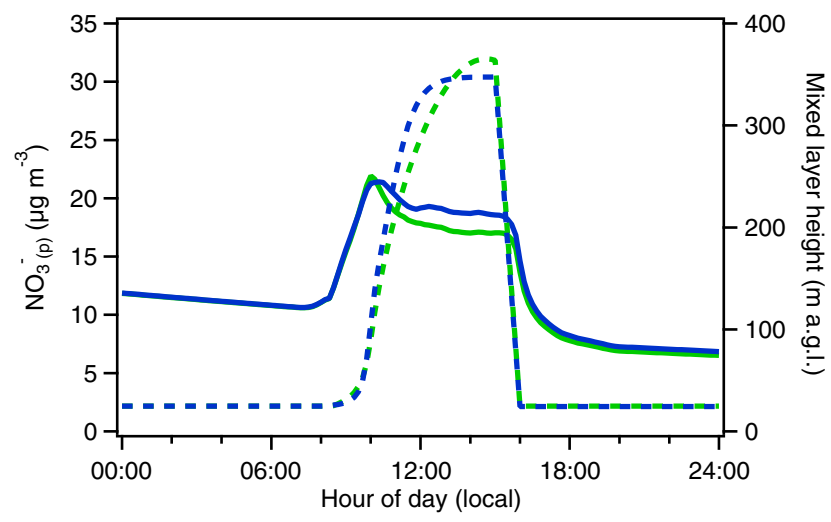

Figure B3. Average modeled surface $\mathrm{NO}_{3}^{-}$(p) (solid lines) using the CLASS model output (green) and a sigmoid fit to the observed ML heights (blue). The ML heights used in the model are shown in dashed lines.

starting at 15:00 LT was assumed. The use of this alternative model yields a diurnal $\mathrm{NO}_{3}^{-}(\mathrm{p})$ profile for Episode 1 that is very similar to that obtained using the CLASS model (Fig. B3). This indicates that the general behavior of the diurnal surface $\mathrm{NO}_{3}^{-}$(p) profile is not particularly sensitive to the treatment of the boundary layer rise and that the results obtained here are robust.

\section{Appendix C: Nocturnal reactions in the $\mathbf{R L}$}

\section{C1 $\mathrm{N}_{2} \mathrm{O}_{5}$ production and heterogeneous reactivity}

The gas-phase and heterogeneous chemistry occurring in the RL was assumed to follow the reaction scheme indicated by Reactions (R1)-(R4). Focusing first on the heterogeneous hydrolysis of $\mathrm{N}_{2} \mathrm{O}_{5}$, one estimate of the night- 
specific average rate coefficients for $\mathrm{N}_{2} \mathrm{O}_{5}$ heterogeneous hydrolysis $\left(k_{\mathrm{N}_{2} \mathrm{O}_{5}}\right)$ is obtained through consideration of the initial concentrations of precursor gases and the observed maximum overnight increase in the $\mathrm{RL} \mathrm{NO}_{3}^{-}(\mathrm{p}), \mathrm{PNO}_{3}^{-}$. More specifically, a 1-D box model including nocturnal gasphase chemistry and heterogeneous reaction of $\mathrm{N}_{2} \mathrm{O}_{5}$ with particles was run iteratively to determine an average $k_{\mathrm{N}_{2} \mathrm{O}_{5}}$ for the night $(19: 00-08: 00 ; 13 \mathrm{~h})$ such that it reproduced the observed $\mathrm{PNO}_{3}^{-}$. The observed chloride at Fresno was small ( $1 \%$ of $\mathrm{PM}_{1.0}$ ) during the episode, and thus formation of nitryl chloride $\left(\mathrm{ClNO}_{2}\right)$ can be reasonably neglected (Young et al., 2016). Since the boundary layer is fairly wellmixed in the afternoon, surface-level observations of $\mathrm{NO}_{x}$, $\mathrm{O}_{3}, \mathrm{NO}_{3}^{-}(\mathrm{p})$, particle wet surface area and temperature at 15:00 LT on the preceding day were used as initial conditions. Based on back-calculated $k_{\mathrm{N}_{2} \mathrm{O}_{5}}$ values, night-specific values of the heterogeneous $\mathrm{N}_{2} \mathrm{O}_{5}$ uptake coefficient $\left(\gamma_{\left.\mathrm{N}_{2} \mathrm{O}_{5}\right)}\right)$ were determined from

$k_{\mathrm{N}_{2} \mathrm{O}_{5}}=\frac{\omega \cdot S_{\mathrm{a}} \cdot \gamma_{\mathrm{N}_{2} \mathrm{O}_{5}}}{4}$,

where $\omega$ is the mean molecular speed of $\mathrm{N}_{2} \mathrm{O}_{5}\left(256 \mathrm{~m} \mathrm{~s}^{-1}\right)$, $S_{\mathrm{a}}$ is the wet particle surface area and $\gamma$ is the $\mathrm{N}_{2} \mathrm{O}_{5}$ heterogeneous uptake coefficient (Brown et al., 2006c). The wet particle surface area was calculated from the observed dry particle size distributions, particle hygroscopicity and $\mathrm{RH}$. The resulting back-calculated $k_{\mathrm{N}_{2} \mathrm{O}_{5}}$ values from Eq. (C1) were in the range $1.3-5.1 \times 10^{-5} \mathrm{~s}^{-1}$. The corresponding back-calculated $\gamma \mathrm{N}_{2} \mathrm{O}_{5}$ values were in the range $2.5 \times 10^{-4}$ to $4.8 \times 10^{-4}$ (Table S1), which as noted in the main text are somewhat smaller than values observed under water-limited conditions in other field studies and lower than expected based on lab experiments (Bertram et al., 2009).

A second estimate of the $\gamma_{\mathrm{N}_{2}} \mathrm{O}_{5}$ values is calculated from the particle composition following Bertram et al. (2009). The calculated $\gamma_{\mathrm{N}_{2} \mathrm{O}_{5}}$ values depend on the particle water content (specifically, the $\left[\mathrm{H}_{2} \mathrm{O}\right] /\left[\mathrm{NO}_{3}^{-}(\mathrm{p})\right]$ and thus $\mathrm{RH}$ ) and the chloride fraction. The composition-calculated $\gamma_{\mathrm{N}_{2}} \mathrm{O}_{5}$ values $\left(\sim 10^{-3}\right)$ are larger than the above back-calculated values and more consistent with the literature although on the lower side of previous measurements (Brown et al., 2006c; Bertram et al., 2009). That the back-calculated $\gamma_{\mathrm{N}_{2} \mathrm{O}_{5}}$ values are smaller than the $\gamma_{\mathrm{N}_{2} \mathrm{O}_{5}}$ calculated from the composition, which is likely a consequence of the $\mathrm{PNO}_{3}^{-}$being an under-estimate relative to the true overnight production in the RL. This is because the observed $\mathrm{PNO}_{3}^{-}$is taken as the difference between the previous afternoon and early-morning $\mathrm{NO}_{3}^{-}$(p) concentration in the aloft RL layer having the maximum morning concentration. This does not account for the influence of advection, which is most likely going to reduce the morning $\mathrm{NO}_{3}^{-}(\mathrm{p})$ relative to if there were no advection.

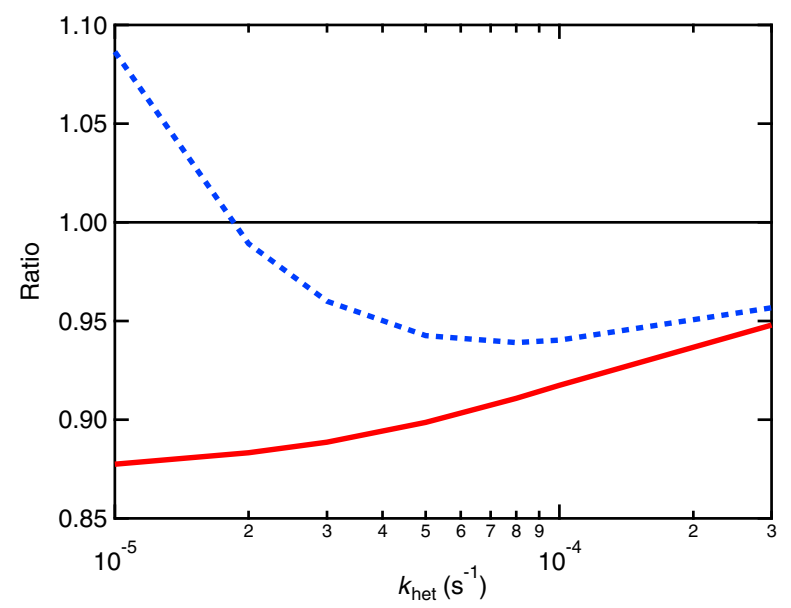

Figure C1. Model results showing the influence of including $\mathrm{NO}_{3}+$ VOC reactions on $\mathrm{HNO}_{3}$ production via the heterogeneous hydrolysis of $\mathrm{N}_{2} \mathrm{O}_{5}$, as a function of the heterogeneous oxidation rate. The red line shows the ratio between the $\mathrm{HNO}_{3}$ produced via $\mathrm{N}_{2} \mathrm{O}_{5}$ hydrolysis when reactions with VOCs are considered and when they are not. Reaction of $\mathrm{NO}_{3}$ with VOCs reduces the $\mathrm{HNO}_{3}$ formed via hydrolysis. The blue line shows the ratio between the total $\mathrm{HNO}_{3}$ produced from either $\mathrm{N}_{2} \mathrm{O}_{5}$ hydrolysis or $\mathrm{NO}_{3}+\mathrm{VOC}$ reactions when reactions with VOCs are considered and when they are not.

\section{C2 Reactions with VOCs}

Not considered above is the reaction of the $\mathrm{NO}_{3}$ radical with VOCs. $\mathrm{NO}_{3}$ radicals react rapidly with alkenes and more slowly with alkanes and other species. $\mathrm{NO}_{3}$ reaction with VOCs can lead to hydrogen abstraction and direct formation of $\mathrm{HNO}_{3}$, especially for reactions with alkanes. For alkenes and aromatics, $\mathrm{NO}_{3}$ reaction typically proceeds via $\mathrm{NO}_{3}$ addition and formation of organic nitrates. The latter would suppress formation of particulate inorganic nitrate but can serve as an important source of particulate organic nitrate (Kiendler-Scharr et al., 2016). Organic nitrate formation has been observed as an important source of summertime organic aerosol in Bakersfield, CA (also in the SJV) (Rollins et al., 2012). VOC concentrations and reactivity are likely much lower during the colder winter compared to the warmer summer (Pusede et al., 2014), and thus reaction of VOCs with $\mathrm{NO}_{3}$ radicals is likely significantly suppressed.

The concentrations of a broad suite of VOCs were measured via whole air canister sampling during DISCOVERAQ. These measurements can be used to assess the potential influence of $\mathrm{NO}_{3}$ reaction with VOCs on $\mathrm{HNO}_{3}$ and $\mathrm{NO}_{3}^{-}$(p) formation. The nitrate reactivity towards each VOC is calculated as $k_{\mathrm{VOC}}+\mathrm{NO}_{3} \cdot\left[\mathrm{VOC}\right.$, where the $k_{\mathrm{VOC}}+\mathrm{NO}_{3}$ is the VOC-specific rate coefficient and [VOC] is the VOC concentration (Ng et al., 2017). Average afternoon VOC concentrations are used, which should be representative of the initial concentrations in the RL. The VOCs are ranked according to their reactivity with $\mathrm{NO}_{3}$. The top 20 VOCs are 
considered explicitly, and all other VOCs are lumped into a common VOC species with the average concentration and $k_{\text {rxn }}$ of these species (Table $\mathrm{S} 2$ ). Reactions between $\mathrm{NO}_{3}$ and alkenes and aromatics are assumed to form (unreactive) organic nitrates, while reactions between $\mathrm{NO}_{3}$ and all other species are assumed to form $\mathrm{HNO}_{3}$ and an organic product species. The influence of $\mathrm{NO}_{3}$ reaction with VOCs on $\mathrm{NO}_{3}^{-}(\mathrm{p})$ is assessed by calculating the overnight production of $\mathrm{HNO}_{3}$ both with and without VOCs using typical afternoon $\mathrm{NO}(3 \mathrm{ppb}), \mathrm{NO}_{2}(20 \mathrm{ppb})$, and $\mathrm{O}_{3}$ (27 ppb) concentrations, and for $k_{\mathrm{N}_{2} \mathrm{O}_{5}}$ concentrations ranging from $1 \times 10^{-5}$ to $3 \times 10^{-4} \mathrm{~s}^{-1}$. $\mathrm{HNO}_{3}$ produced from $\mathrm{N}_{2} \mathrm{O}_{5}$ hydrolysis is tracked separately from $\mathrm{HNO}_{3}$ produced from $\mathrm{NO}_{3}$ reaction with VOCs. The $\mathrm{HNO}_{3}$ production via $\mathrm{N}_{2} \mathrm{O}_{5}$ hydrolysis decreases marginally when VOC reactions are included. The $\mathrm{HNO}_{3}$ suppression ranges from $\sim 12 \%$ for $k_{\mathrm{N}_{2} \mathrm{O}_{5}}=$ $10^{-5} \mathrm{~s}^{-1}$ to $5 \%$ for $k_{\mathrm{N}_{2} \mathrm{O}_{5}}=10^{-4} \mathrm{~s}^{-1}$ (Fig. C1). However, the calculations indicate that much of this $\mathrm{HNO}_{3}$ suppression is potentially offset by $\mathrm{HNO}_{3}$ production from reaction of $\mathrm{NO}_{3}$ with non-alkene or aromatic compounds. For larger $k_{\mathrm{N}_{2} \mathrm{O}_{5}}$ values the net suppression is only $5 \%$, with the suppression decreasing as $k_{\mathrm{N}_{2} \mathrm{O}_{5}}$ decreases. At the lowest $k_{\mathrm{N}_{2} \mathrm{O}_{5}}$ $\left(10^{-5} \mathrm{~s}^{-1}\right)$ the calculations indicate that the inclusion of the $\mathrm{NO}_{3}+$ VOC reaction actually leads to an increase in the net $\mathrm{HNO}_{3}$ production (Fig. C1). Overall, these calculations suggest that the reaction of $\mathrm{NO}_{3}$ with VOCs has a relatively minor influence on the overnight local production of $\mathrm{HNO}_{3}$ in the RL.

\section{Appendix D: Box model details}

The box model for calculating the time-varying surface concentrations of $\mathrm{NO}_{3}^{-}$(p) accounts for (i) mixing of air in the aloft RL with the surface air, including the time-dependent rise and fall of the boundary layer; (ii) daytime photochemical production of $\mathrm{HNO}_{3}$ from the $\mathrm{OH}+\mathrm{NO}_{2}$ reaction; (iii) $T$ - and RH-dependent gas-particle partitioning of ammonium nitrate; (iv) afternoon entrainment of air from the free troposphere; (iv) competition between condensation of $\mathrm{HNO}_{3}$ onto existing suspended particles versus loss via dry deposition; and (v) dry deposition of particulate $\mathrm{NO}_{3}^{-}(\mathrm{p})$. The kinetic equations were solved in the data analysis program Igor (Wavemetrics) and set up using the KinSim Igor package, developed by Harold Stark (http://www.igorexchange. com/node/1333). The model was initialized with the observed $\mathrm{NO}_{3}^{-}$(p) measured by the AMS at surface level at 12:00 LT and run in $10 \mathrm{~min}$ steps. For each time step, the photochemical production equations used the instantaneous observed $\mathrm{NO}_{2}$ and temperature and estimated $\mathrm{OH}$ concentration and $\mathrm{ML}$ height. The fraction of $\mathrm{NO}_{3}^{-}$in gas phase, $f$, for each time step was determined based on the instantaneous conditions using the chemical thermodynamic model, ISORROPIA II, in the forward mode, with the phase state set as metastable (Fountoukis and Nenes, 2007). ISORROPIA was initialized with the observed particulate composition, specifically $\mathrm{NO}_{3}^{-}$and $\mathrm{SO}_{4}^{2-}$ (AMS) and $\mathrm{Na}^{+}, \mathrm{K}^{+}$and $\mathrm{Cl}^{-}$ (PILS). (The PILS and AMS sampled particles of somewhat different size, with the PILS sampling $\mathrm{PM}_{3}$ and the AMS $\mathrm{PM}_{1}$. The AMS observations are available at higher time resolution and are thus preferable for use here. However, there are challenges in the quantitative characterization of $\mathrm{Na}^{+}, \mathrm{K}^{+}$and $\mathrm{Cl}^{-}$when using the AMS, and thus the PILS was used instead for these species. Comparison of the AMS and PILS $\mathrm{NO}_{3}^{-}$and $\mathrm{SO}_{4}^{2-}$ indicates that the AMS-measured concentrations are $\sim 10 \%$ lower than for the PILS, which is attributable to a mass between 1 and $3 \mu \mathrm{m}$, Parworth et al., 2017. The $\mathrm{Na}^{+}, \mathrm{K}^{+}$and $\mathrm{Cl}^{-}$ions are minor components of the total $\mathrm{PM}_{3}$, and thus the AMS-PILS difference has a minor influence on the calculations here.) Since the PILS was not functioning on 18 January, 2013, the ionic compositions of $\mathrm{K}^{+}$and $\mathrm{Cl}^{-}$were estimated from the linear relationship between the PILS and AMS composition (Eqs. C1C2). Since $\mathrm{Na}^{+}$measured by PILS was generally constant during the episode, it was assumed to be the same on 18th. The diurnally varying concentrations of total $\mathrm{NH}_{3}(\mathrm{~g}+\mathrm{p})$ for ISORROPIA were calculated as the sum of $\mathrm{NH}_{4}^{+}(\mathrm{p})$ measured by AMS and $\mathrm{NH}_{3(\mathrm{~g})}$ measured by the denuder at the surface in Fresno; since the denuder measurements were averages over $6-7 \mathrm{~h}$, the $\mathrm{NH}_{3(\mathrm{~g})}$ concentration was linearly interpolated between the individual measurements to allow for estimation with higher time resolution. The $6-7 \mathrm{~h}$ average denuder-based $\mathrm{NH}_{3(\mathrm{~g})}$ measurements compare reasonably with the point $\mathrm{NH}_{3(\mathrm{~g})}$ measurements made onboard the P3-B at the lowest altitude over Fresno. The fraction of $\mathrm{NO}_{3}^{-}$ predicted to be in the gas phase was also found to be in generally good agreement with the observations (Fig. D1; Parworth et al., 2017).

$$
\begin{aligned}
& {\left[\mathrm{Cl}^{-}\right]=1.24 \cdot\left[\mathrm{Cl}^{-}\right]_{\mathrm{AMS}}} \\
& {\left[\mathrm{K}^{+}\right]=-0.036 \cdot[\mathrm{Org}]_{\mathrm{AMS}}}
\end{aligned}
$$

As the boundary layer rises, starting around 08:00 LT, and air from the $\mathrm{RL}$ is mixed into the surface air, the instantaneous $\mathrm{NO}_{3}^{-}(\mathrm{p})$ concentration at the surface $\left(\left[\mathrm{NO}_{3}^{-}(\mathrm{p})\right]_{\text {surf }}\right)$ is calculated as

$$
\begin{aligned}
& {\left[_{\left.\mathrm{NO}_{3}^{-}(\mathrm{p})\right]_{\text {surf }, t}=\left[\mathrm{NO}_{3}^{-}(\mathrm{p})\right]_{\text {surf }, t-1}}\right.} \\
& \quad+\left\{\left[\mathrm{NO}_{3}^{-}(\mathrm{p})\right]_{\text {surf }, t-1}-\left[\mathrm{NO}_{3}^{-}(\mathrm{p})\right]_{\mathrm{RL}, t}\right\} \\
& \quad \times\left\{1-\frac{w_{\mathrm{e}} \cdot \Delta t}{\mathrm{BLH}}\right\},
\end{aligned}
$$

where $t$ and $t-1$ represent the current and previous time steps, respectively; BLH is the boundary layer height (m a.g.l.); $w_{\mathrm{e}}$ is the entrainment velocity; and $\left[\mathrm{NO}_{3}^{-}(\mathrm{p})\right]_{\mathrm{RL}, t}$ is the concentration of $\mathrm{NO}_{3}^{-}(\mathrm{p})$ in the layer of air that is entrained. Between 08:00 LT and (approximately) noon, the vertical $\mathrm{NO}_{3}^{-}$(p) profile within the remaining $\mathrm{RL}$ (above the 

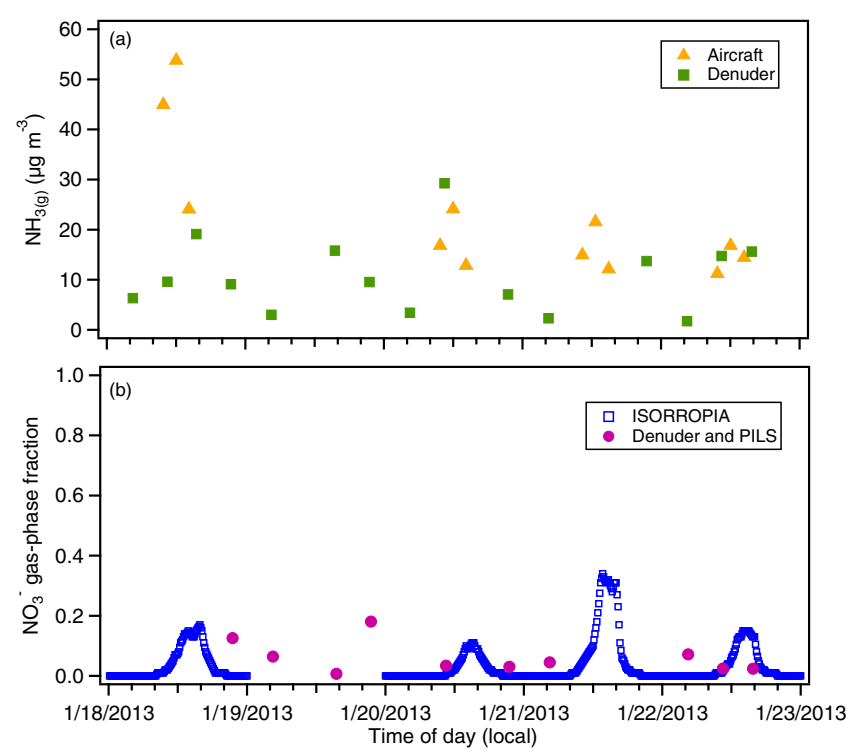

Figure D1. (a) Time series of $\mathrm{NH}_{3(\mathrm{~g})}\left(\mu \mathrm{g} \mathrm{m}^{-3}\right)$ measured with the denuder at the surface (green squares) and at the lowest altitudes by the chemical ionization mass spectrometer onboard P3-B aircraft (yellow triangles). (B) The nitrate gas-phase fraction estimated by ISORROPIA (blue squares) and the observed fraction determined from the denuder $\mathrm{HNO}_{3(\mathrm{~g})}$ and $\mathrm{PILS} \mathrm{NO}_{3}^{-}$(p) measurements (pink circles) (Parworth et al., 2017).

instantaneous BLH) is assumed to remain unchanged from the early-morning-observed profile. The vertical $\mathrm{NO}_{3}^{-}$(p) profile is updated to that observed during the second flight once the BLH (from the CLASS model) reaches the ML height observed around noon.

The daytime photochemical production of $\mathrm{HNO}_{3}$ was calculated from Reaction (DR1) (Burkholder et al., 2015, http://jpldataeval.jpl.nasa.gov).

$\mathrm{NO}_{2}+\mathrm{OH} \rightarrow \mathrm{HNO}_{3} ; k_{\mathrm{OH}}=2.8 \times 10^{-11} \mathrm{~cm}^{-3}$ molecule ${ }^{-1} \mathrm{~s}^{-1}$

(DR1)

The $\mathrm{OH}$ concentration at a given time step was assumed to scale with the solar radiation flux (SR) as

$[\mathrm{OH}]_{t}=\left(\frac{\mathrm{SR}_{t}}{\mathrm{SR}_{\max }}\right)[\mathrm{OH}]_{\max }$,

where the maximum daytime $\mathrm{OH}$ concentration is assumed to be $[\mathrm{OH}]_{\max }=1 \times 10^{6}$ molecules $\mathrm{cm}^{-3}$, after Pusede et al. (2016). The rate coefficient for condensation of $\mathrm{HNO}_{3(\mathrm{~g})}$ onto suspended particulates, $k_{\text {cond }}$, was calculated based on collision theory (Seinfeld and Pandis, 2006) as

$k_{\mathrm{cond}}=\sum_{i} \beta_{i} \cdot 2 \cdot D_{\mathrm{p}, i} \cdot D \cdot 10^{-4} \cdot \mathrm{d} N_{i}$,

where the summation is over particle size, $D_{\mathrm{p}, i}$ is the mean particle diameter in the size bin $i(\mathrm{~m})$ and $\mathrm{d} N_{i}$ is the number concentration in the size bin $i\left(\mathrm{~m}^{-3}\right)$. The term $\beta_{i}$ is the sizedependent Fuchs correction in the continuum regime given by

$\beta_{i}=0.75 \cdot \frac{1+\mathrm{Kn}}{\mathrm{Kn}^{2}+1.283 \cdot \mathrm{Kn}+0.75}$,

where $\mathrm{Kn}=\lambda / D_{\mathrm{p}, i}$ and $\lambda$ is the gas mean free path $(65 \mathrm{~nm})$. The parameter $D$ is the diffusion coefficient of $\mathrm{HNO}_{3}$ gas in air $\left(\mathrm{cm}^{2} \mathrm{~s}^{-1}\right)$ given by De Andrade et al. (1992):

$D=10^{-4.7773} \cdot T^{1.366}$,

where $T$ is ambient temperature $(\mathrm{K})$. The corresponding evaporation rate coefficient $\left(k_{\text {evap }}\right)$ is determined as

$k_{\text {evap }}=\frac{K_{\text {eqm }}}{k_{\text {cond }}}$,

where $K_{\text {eqm }}$ is the instantaneous (temperature and $\mathrm{RH}$ dependent) equilibrium partitioning coefficient for ammonium nitrate. The rate coefficient for loss of gas-phase $\mathrm{HNO}_{3}$ or $\mathrm{NO}_{3}^{-}$(p) from dry deposition, $k_{\mathrm{dep}}\left(\mathrm{s}^{-1}\right)$, is

$k_{\mathrm{dep}}=\frac{v_{\mathrm{d}}}{\mathrm{BLH}}$,

where $v_{\mathrm{d}}$ is the deposition velocity $\left(\mathrm{cm} \mathrm{s}^{-1}\right)$ and BLH is the time-dependent boundary layer height. The $\mathrm{HNO}_{3(\mathrm{~g})}$ deposition velocity has been shown to vary linearly with wind speed (Ma and Daggupaty, 2000). Here, it was assumed that

$v_{\mathrm{d}}=1+9 \cdot\left(\frac{\mathrm{ws}-\mathrm{ws}_{\min }}{\mathrm{ws}_{\max }-\mathrm{ws}_{\min }}\right)$,

where ws is the observed wind speed and where $\mathrm{ws}_{\min }$ and $\mathrm{ws}_{\max }$ are the minimum and maximum values observed. The bounds of Eq. (C10) (lower limit $v_{\mathrm{d}}=1 \mathrm{~cm} \mathrm{~s}^{-1}$ and upper limit $10 \mathrm{~cm} \mathrm{~s}^{-1}$ ) were chosen to span previously observed ranges. While the accuracy of the empirical Eq. (C10) is not known, we note that use of a constant $v_{\mathrm{d}}$ of $0.07 \mathrm{~cm} \mathrm{~s}^{-1}$ does not change the box model output substantially (Fig. S14). Of course, if the actual $v_{\mathrm{d}}$ were lower than estimated here, the influence of dry deposition on $\mathrm{NO}_{3}^{-}$(p) concentrations would be decreased. The $\mathrm{NO}_{3}^{-}$(p) deposition velocity was assumed to be $0.01 \mathrm{~cm} \mathrm{~s}^{-1}$, which is consistent with the much slower deposition of particles than soluble gases such as $\mathrm{HNO}_{3}$. Dry deposition occurred both during the daytime and nighttime. 


\section{The Supplement related to this article is available online at https://doi.org/10.5194/acp-17-14747-2017- supplement.}

Author contributions. GP and CDC wrote the paper, with contributions from all authors. CP, XZ, HK, AJB, LDZ, JBN, QZ and CDC made the measurements. GP, THB, ICF and CDC contributed to the modeling efforts. CDC and QZ designed the project.

Acknowledgements. This work was funded by the California Air Resources Board (14-307), and the DISCOVER-AQ campaign was supported by NASA. Ian C. Faloona is supported in part by the California Agricultural Experiment Station (Hatch project CAD-LAW-2229-H). The authors thank the entire DISCOVER-AQ science team for their contributions to the DISCOVER-AQ dataset. Sally Pusede (University of Virginia), Ron Cohen (UC Berkeley) and Mike Kleeman (UC Davis) are thanked for their particularly useful comments and discussion.

Edited by: Frank Dentener

Reviewed by: two anonymous referees

\section{References}

American Lung Association: State of the air 2014, Report, p. 13, http://www.stateoftheair.org/2014/assets/ ALA-SOTA-2014-Full.pdf (last access: 3 April 2017), 2014.

Baasandorj, M., Hoch, S. W., Bares, R., Lin, J. C., Brown, S. S., Millet, D. B., Martin, R., Kelly, K., Zarzana, K. J., Whiteman, C. D., Dube, W. P., Tonnesen, G., Jaramillo, I. C., and Sohl, J.: Coupling between Chemical and Meteorological Processes under Persistent Cold-Air Pool Conditions: Evolution of Wintertime $\mathrm{PM}_{2.5}$ Pollution Events and $\mathrm{N}_{2} \mathrm{O}_{5}$ Observations in Utah's Salt Lake Valley, Environ. Sci. Technol., 51, 5941-5950, https://doi.org/10.1021/acs.est.6b06603, 2017.

Bao, J.-W., Michelson, S. A., Persson, P. O. G., Djalalova, I. V., and Wilczak, J. M.: Observed and WRF-Simulated Low-Level Winds in a High-Ozone Episode during the Central California Ozone Study, J. Appl. Meteorol. Clim., 47, 2372-2394, https://doi.org/10.1175/2008JAMC1822.1, 2008.

Bertram, T. H., Thornton, J. A., Riedel, T. P., Middlebrook, A. M., Bahreini, R., Bates, T. S., Quinn, P. K., and Coffman, D. J.: Direct observations of $\mathrm{N}_{2} \mathrm{O}_{5}$ reactivity on ambient aerosol particles, Geophys. Res. Lett., 36, L19803, https://doi.org/10.1029/2009gl040248, 2009.

Beyersdorf, A. J., Ziemba, L. D., Chen, G., Corr, C. A., Crawford, J. H., Diskin, G. S., Moore, R. H., Thornhill, K. L., Winstead, E. L., and Anderson, B. E.: The impacts of aerosol loading, composition, and water uptake on aerosol extinction variability in the Baltimore-Washington, D.C. region, Atmos. Chem. Phys., 16, 1003-1015, https://doi.org/10.5194/acp-16-1003-2016, 2016.

Bianco, L., Djalalova, I. V., King, C. W., and Wilczak, J. M.: Diurnal Evolution and Annual Variability of Boundary-Layer Height and Its Correlation to Other Meteorological Variables in Cali- fornia's Central Valley, Bound.-Lay. Meteorol., 140, 491-511, https://doi.org/10.1007/s10546-011-9622-4, 2011.

Bigi, A., Ghermandi, G., and Harrison, R. M.: Analysis of the air pollution climate at a background site in the Po valley, J. Environ. Monitor., 14, 552-563, https://doi.org/10.1039/C1EM10728C, 2012.

Brent, L. C., Thorn, W. J., Gupta, M., Leen, B., Stehr, J. W., He, H., Arkinson, H. L., Weinheimer, A., Garland, C., Pusede, S. E., Wooldridge, P. J., Cohen, R. C., and Dickerson, R. R.: Evaluation of the use of a commercially available cavity ringdown absorption spectrometer for measuring $\mathrm{NO} 2$ in flight, and observations over the Mid-Atlantic States, during DISCOVER-AQ, J. Atmos. Chem., 72, 503-521, https://doi.org/10.1007/s10874-013-92656, 2015.

Brown, S. G., Hyslop, N. P., Roberts, P. T., McCarthy, M. C., and Lurmann, F. W.: Wintertime Vertical Variations in Particulate Matter (PM) and Precursor Concentrations in the San Joaquin Valley during the California Regional Coarse PM/Fine PM Air Quality Study, J. Air Waste Ma., 56, 1267-1277, https://doi.org/10.1080/10473289.2006.10464583, 2006a.

Brown, S. S., Neuman, J. A., Ryerson, T. B., Trainer, M., Dubé, W. P., Holloway, J. S., Warneke, C., de Gouw, J. A., Donnelly, S. G., Atlas, E., Matthew, B., Middlebrook, A. M., Peltier, R., Weber, R. J., Stohl, A., Meagher, J. F., Fehsenfeld, F. C., and Ravishankara, A. R.: Nocturnal odd-oxygen budget and its implications for ozone loss in the lower troposphere, Geophys. Res. Lett., 33, L08801, https://doi.org/10.1029/2006GL025900, 2006b.

Brown, S. S., Ryerson, T. B., Wollny, A. G., Brock, C. A., Peltier, R., Sullivan, A. P., Weber, R. J., Dube, W. P., Trainer, M., Meagher, J. F., Fehsenfeld, F. C., and Ravishankara, A. R.: Variability in nocturnal nitrogen oxide processing and its role in regional air quality, Science, 311, 67-70, https://doi.org/10.1126/science.1120120, 2006c.

Burkholder, J. B., Sander, S. P., Abbatt, J., Barker, J. R., Huie, R. E., Kolb, C. E., Kurylo, M. J., Orkin, V. L., Wilmouth, D. M., and Wine, P. H.: Chemical Kinetics and Photochemical Data for Use in Atmospheric Studies, Evaluation No. 18, Jet Propulsion Laboratory, Pasadena, http://jpldataeval.jpl.nasa.gov (last access: 29 November 2017), 2015.

Cabañas, B., Salgado, S., Martín, P., Baeza, M. T., and Martínez, E.: Night-time Atmospheric Loss Process for Unsaturated Aldehydes:? Reaction with $\mathrm{NO}_{3}$ Radicals, J. Phys. Chem. A, 105 , 4440-4445, https://doi.org/10.1021/jp0029459, 2001.

Cappa, C. D., Onasch, T. B., Massoli, P., Worsnop, D. R., Bates, T. S., Cross, E. S., Davidovits, P., Hakala, J., Hayden, K. L., Jobson, B. T., Kolesar, K. R., Lack, D. A., Lerner, B. M., Li, S.-M., Mellon, D., Nuaaman, I., Olfert, J. S., Petäjä, T., Quinn, P. K., Song, C., Subramanian, R., Williams, E. J., and Zaveri, R. A.: Radiative Absorption Enhancements Due to the Mixing State of Atmospheric Black Carbon, Science, 337, 1078-1081, https://doi.org/10.1126/science.1223447, 2012.

Chow, J. C., Watson, J. G., Lowenthal, D. H., Hackney, R., Magliano, K., Lehrman, D., and Smith, T.: Temporal variations of $\mathrm{PM}_{2.5}, \mathrm{PM}_{10}$, and gaseous precursors during the 1995 integrated monitoring study in central California, J. Air Waste Ma., 49, 16-24, 1999.

Chow, J. C., Chen, L. W. A., Watson, J. G., Lowenthal, D. H., Magliano, K. A., Turkiewicz, K., and Lehrman, D. 
E.: $\mathrm{PM}_{2.5}$ chemical composition and spatiotemporal variability during the California Regional $\mathrm{PM}_{10} / \mathrm{PM}_{2.5}$ Air Quality Study (CRPAQS), J. Geophys. Res., 111, D10S04, https://doi.org/10.1029/2005JD006457, 2006.

Chow, J. C., Watson, J. G., Lowenthal, D. H., and Magliano, K. L.: Size-resolved aerosol chemical concentrations at rural and urban sites in Central California, USA, Atmos. Res., 90, 243-252, https://doi.org/10.1016/j.atmosres.2008.03.017, 2008.

Crawford, J. H. and Pickering, K. E.: DISCOVER-AQ: Advancing strategies for air quality observations in the next decade, Environ. Manage, 4-7, 2014.

Curci, G., Ferrero, L., Tuccella, P., Barnaba, F., Angelini, F., Bolzacchini, E., Carbone, C., Denier van der Gon, H. A. C., Facchini, M. C., Gobbi, G. P., Kuenen, J. P. P., Landi, T. C., Perrino, C., Perrone, M. G., Sangiorgi, G., and Stocchi, P.: How much is particulate matter near the ground influenced by upperlevel processes within and above the PBL? A summertime case study in Milan (Italy) evidences the distinctive role of nitrate, Atmos. Chem. Phys., 15, 2629-2649, https://doi.org/10.5194/acp15-2629-2015, 2015.

Day, D. A., Wooldridge, P. J., Dillon, M. B., Thornton, J. A., and Cohen, R. C.: A thermal dissociation laser-induced fluorescence instrument for in situ detection of $\mathrm{NO}_{2}$, peroxy nitrates, alkyl nitrates, and $\mathrm{HNO}_{3}$, J. Geophys. Res., 107, D64046, https://doi.org/10.1029/2001JD000779, 2002.

De Andrade, J. B., De Aragão, N. M., and Araújo, F. R. J.: Nitric Acid-Air Diffusion Coefficient: Experimental Determination Using a Diffusion Cell, Int. J. Environ. An. Ch., 49, 103-109, https://doi.org/10.1080/03067319208028130, 1992.

Dentener, F. J. and Crutzen, P. J.: Reaction of $\mathrm{N}_{2} \mathrm{O}_{5}$ on tropospheric aerosols - Impact on the global distributions of $\mathrm{NO}_{x}, \mathrm{O}_{3}$, and $\mathrm{OH}, \mathrm{J}$. Geophys. Res., 98, 7149-7163, https://doi.org/10.1029/92jd02979, 1993.

Farmer, D. K., Chen, Q., Kimmel, J. R., Docherty, K. S., Nemitz, E., Artaxo, P. A., Cappa, C. D., Martin, S. T., and Jimenez, J. L.: Chemically Resolved Particle Fluxes Over Tropical and Temperate Forests, Aerosol Sci. Technol., 47, 818-830, https://doi.org/10.1080/02786826.2013.791022, 2013.

Fountoukis, C. and Nenes, A.: ISORROPIA II: a computationally efficient thermodynamic equilibrium model for $\mathrm{K}^{+}-$ $\mathrm{Ca}^{2+}-\mathrm{Mg}^{2+}-\mathrm{NH}_{4}^{+}-\mathrm{Na}^{+}-\mathrm{SO}_{4}^{2-}-\mathrm{NO}_{3}^{-}-\mathrm{Cl}^{-}-\mathrm{H}_{2} \mathrm{O}$ aerosols, Atmos. Chem. Phys., 7, 4639-4659, https://doi.org/10.5194/acp-74639-2007, 2007.

Ge, X., Setyan, A., Sun, Y., and Zhang, Q.: Primary and secondary organic aerosols in Fresno, California during wintertime: Results from high resolution aerosol mass spectrometry, J. Geophys. Res., 117, D19301, https://doi.org/10.1029/2012JD018026, 2012.

Horii, C. V., Munger, J. W., Wofsy, S. C., Zahniser, M., Nelson, D., and McManus, J. B.: Atmospheric reactive nitrogen concentration and flux budgets at a Northeastern US forest site, Agr. Forest Meteorol., 133, 210-225, https://doi.org/10.1016/j.agrformet.2004.08.009, 2005.

Janssen, R. H. H., Vilà-Guerau de Arellano, J., Ganzeveld, L. N., Kabat, P., Jimenez, J. L., Farmer, D. K., van Heerwaarden, C. C., and Mammarella, I.: Combined effects of surface conditions, boundary layer dynamics and chemistry on diurnal SOA evolution, Atmos. Chem. Phys., 12, 6827-6843, https://doi.org/10.5194/acp-12-6827-2012, 2012.
Janssen, R. H. H., Vilà-Guerau de Arellano, J., Jimenez, J. L., Ganzeveld, L. N., Robinson, N. H., Allan, J. D., Coe, H., and Pugh, T. A. M.: Influence of boundary layer dynamics and isoprene chemistry on the organic aerosol budget in a tropical forest, J. Geophys. Res.-Atmos., 118, 9351-9366, https://doi.org/10.1002/jgrd.50672, 2013.

Kiendler-Scharr, A., Mensah, A. A., Friese, E., Topping, D., Nemitz, E., Prevot, A. S. H., Äijälä, M., Allan, J., Canonaco, F., Canagaratna, M., Carbone, S., Crippa, M., Dall Osto, M., Day, D. A., De Carlo, P., Di Marco, C. F., Elbern, H., Eriksson, A., Freney, E., Hao, L., Herrmann, H., Hildebrandt, L., Hillamo, R., Jimenez, J. L., Laaksonen, A., McFiggans, G., Mohr, C., O'Dowd, C., Otjes, R., Ovadnevaite, J., Pandis, S. N., Poulain, L., Schlag, P., Sellegri, K., Swietlicki, E., Tiitta, P., Vermeulen, A., Wahner, A., Worsnop, D., and Wu, H. C.: Organic nitrates from night-time chemistry are ubiquitous in the European submicron aerosol, Geophys. Res. Lett., 43, 7735-7744, https://doi.org/10.1002/2016GL069239, 2016.

Kim, H., Zhang, Q., Bae, G.-N., Kim, J. Y., and Lee, S. B.: Sources and atmospheric processing of winter aerosols in Seoul, Korea: insights from real-time measurements using a high-resolution aerosol mass spectrometer, Atmos. Chem. Phys., 17, 2009-2033, https://doi.org/10.5194/acp-17-2009-2017, 2017.

Kim, Y. J., Spak, S. N., Carmichael, G. R., Riemer, N., and Stanier, C. O.: Modeled aerosol nitrate formation pathways during wintertime in the Great Lakes region of North America, J. Geophys. Res.-Atmos., 119, 12420-12445, https://doi.org/10.1002/2014jd022320, 2014.

Kleeman, M. J., Ying, Q., and Kaduwela, A.: Control strategies for the reduction of airborne particulate nitrate in California's San Joaquin Valley, Atmos. Environ., 39, 5325-5341, https://doi.org/10.1016/j.atmosenv.2005.05.044, 2005.

Kondo, A., Kaga, A., K., Imamura, Inoue, Y., Sugisawa, M., Shrestha, M. L., and Sapkota, B.: Investigation of air pollution concentration in Kathmandu valley during winter season, J. Environ. Sci., 17, 1008-1013, 2005.

Kuprov, R., Eatough, D. J., Cruickshank, T., Olson, N., Cropper, P. M., and Hansen, J. C.: Composition and secondary formation of fine particulate matter in the Salt Lake Valley: Winter 2009, J. Air Waste Ma., 64, 957-969, https://doi.org/10.1080/10962247.2014.903878, 2014.

Lack, D. A., Richardson, M. S., Law, D., Langridge, J. M., Cappa, C. D., McLaughlin, R. J., and Murphy, D. M.: Aircraft instrument for comprehensive characterization of aerosol optical properties, Part 2: Black and brown carbon absorption and absorption enhancement measured with photo acoustic spectroscopy, Aerosol Sci. Technol., 46, 555-568, https://doi.org/10.1080/02786826.2011.645955, 2012.

Lowe, D., Archer-Nicholls, S., Morgan, W., Allan, J., Utembe, S., Ouyang, B., Aruffo, E., Le Breton, M., Zaveri, R. A., Di Carlo, P., Percival, C., Coe, H., Jones, R., and McFiggans, G.: WRF-Chem model predictions of the regional impacts of $\mathrm{N}_{2} \mathrm{O}_{5}$ heterogeneous processes on night-time chemistry over north-western Europe, Atmos. Chem. Phys., 15, 1385-1409, https://doi.org/10.5194/acp-15-1385-2015, 2015.

Lurmann, F. W., Brown, S. G., McCarthy, M. C., and Roberts, P. T.: Processes Influencing Secondary Aerosol Formation in the San Joaquin Valley during Winter, J. Air Waste Ma. 56, 1679-1693, https://doi.org/10.1080/10473289.2006.10464573, 2006. 
Ma, J. and Daggupaty, S. M.: Effective Dry Deposition Velocities for Gases and Particles over Heterogeneous Terrain, J. Appl. Meteorol., 39, 1379-1390, https://doi.org/10.1175/15200450(2000)039<1379:EDDVFG>2.0.CO;2, 2000.

Massoli, P., Bates, T. S., Quinn, P. K., Lack, D. A., Baynard, T., Lerner, B. M., Tucker, S. C., Brioude, J., Stohl, A., and Williams, E. J.: Aerosol optical and hygroscopic properties during TexAQS-GoMACCS 2006 and their impact on aerosol direct radiative forcing, J. Geophys. Res., 114, D00F07, https://doi.org/10.1029/2008JD011604, 2009.

Meyers, T., Huebert, B., and Hicks, B.: $\mathrm{HNO}_{3}$ deposition to a deciduous forest, Bound.-Lay. Meteorol., 49, 395-410, https://doi.org/10.1007/BF00123651, 1989.

NASA Atmospheric Science Data Center: DISCOVER-AQ data and information, https://doi.org/10.5067/Aircraft/DISCOVERAQ/Aerosol-TraceGas, last access: 26 January 2017.

Ng, N. L., Brown, S. S., Archibald, A. T., Atlas, E., Cohen, R. C., Crowley, J. N., Day, D. A., Donahue, N. M., Fry, J. L., Fuchs, H., Griffin, R. J., Guzman, M. I., Herrmann, H., Hodzic, A., Iinuma, Y., Jimenez, J. L., Kiendler-Scharr, A., Lee, B. H., Luecken, D. J., Mao, J., McLaren, R., Mutzel, A., Osthoff, H. D., Ouyang, B., Picquet-Varrault, B., Platt, U., Pye, H. O. T., Rudich, Y., Schwantes, R. H., Shiraiwa, M., Stutz, J., Thornton, J. A., Tilgner, A., Williams, B. J., and Zaveri, R. A.: Nitrate radicals and biogenic volatile organic compounds: oxidation, mechanisms, and organic aerosol, Atmos. Chem. Phys., 17, 2103-2162, https://doi.org/10.5194/acp-17-2103-2017, 2017.

Nowak, J. B., Neuman, J. A., Bahreini, R., Brock, C. A., Middlebrook, A. M., Wollny, A. G., Holloway, J. S., Peischl, J., Ryerson, T. B., and Fehsenfeld, F. C.: Airborne observations of ammonia and ammonium nitrate formation over Houston, Texas, J. Geophys. Res., 115, D22304, https://doi.org/10.1029/2010JD014195, 2010.

Ouwersloot, H. G. and Vilà-Guerau de Arellano, J.: Analytical Solution for the Convectively-Mixed Atmospheric Boundary Layer, Bound.-Lay. Meteorol., 148, 557-583, https://doi.org/10.1007/s10546-013-9816-z, 2013.

Parworth, C. L., Young, D. E., Kim, H., Zhang, X., Cappa, C. D., Collier, S., and Zhang, Q.: Wintertime water-soluble aerosol composition and particle water content in Fresno, California: Results from DISCOVER-AQ 2013, J. Geophys. Res.-Atmos., 122, 3155-3170, https://doi.org/10.1002/2016JD026173, 2017.

Petters, M. D. and Kreidenweis, S. M.: A single parameter representation of hygroscopic growth and cloud condensation nucleus activity, Atmos. Chem. Phys., 7, 1961-1971, https://doi.org/10.5194/acp-7-1961-2007, 2007.

Pusede, S. E., Gentner, D. R., Wooldridge, P. J., Browne, E. C., Rollins, A. W., Min, K.-E., Russell, A. R., Thomas, J., Zhang, L., Brune, W. H., Henry, S. B., DiGangi, J. P., Keutsch, F. N., Harrold, S. A., Thornton, J. A., Beaver, M. R., St. Clair, J. M., Wennberg, P. O., Sanders, J., Ren, X., VandenBoer, T. C., Markovic, M. Z., Guha, A., Weber, R., Goldstein, A. H., and Cohen, R. C.: On the temperature dependence of organic reactivity, nitrogen oxides, ozone production, and the impact of emission controls in San Joaquin Valley, California, Atmos. Chem. Phys., 14, 3373-3395, https://doi.org/10.5194/acp-143373-2014, 2014.

Pusede, S. E., Duffey, K. C., Shusterman, A. A., Saleh, A., Laughner, J. L., Wooldridge, P. J., Zhang, Q., Parworth, C. L., Kim,
H., Capps, S. L., Valin, L. C., Cappa, C. D., Fried, A., Walega, J., Nowak, J. B., Weinheimer, A. J., Hoff, R. M., Berkoff, T. A., Beyersdorf, A. J., Olson, J., Crawford, J. H., and Cohen, R. C.: On the effectiveness of nitrogen oxide reductions as a control over ammonium nitrate aerosol, Atmos. Chem. Phys., 16, 25752596, https://doi.org/10.5194/acp-16-2575-2016, 2016.

Riemer, N., Vogel, H., Vogel, B., Schell, B., Ackermann, I., Kessler, C., and Hass, H.: Impact of the heterogeneous hydrolysis of $\mathrm{N}_{2} \mathrm{O}_{5}$ on chemistry and nitrate aerosol formation in the lower troposphere under photosmog conditions, J. Geophys. Res., 108, D44144, https://doi.org/10.1029/2002jd002436, 2003.

Rollins, A. W., Browne, E. C., Min, K.-E., Pusede, S. E., Wooldridge, P. J., Gentner, D. R., Goldstein, A. H., Liu, S., Day, D. A., Russell, L. M., and Cohen, R. C.: Evidence for $\mathrm{NO}_{x}$ Control over Nighttime SOA Formation, Science, 337, 1210-1212, https://doi.org/10.1126/science.1221520, 2012.

Sachse, G. W., Hill, G. F., Wade, L. O., and Perry, M. G.: Fastresponse, high-precision carbon monoxide sensor using a tunable diode laser absorption technique, J. Geophys. Res., 92, 20712081, https://doi.org/10.1029/JD092iD02p02071, 1987.

San Joaquin Valley Air Pollution Control District: San Joaquin Airshed 2003 PM10 Plan, available at: http://www.valleyair.org/ Air_Quality_Plans/AQ_plans_PM_2003PlanTOC.htm (last access: 20 June 2016), 2003.

Schiferl, L. D., Heald, C. L., Nowak, J. B., Holloway, J. S., Neuman, J. A., Bahreini, R., Pollack, I. B., Ryerson, T. B., Wiedinmyer, C., and Murphy, J. G.: An investigation of ammonia and inorganic particulate matter in California during the CalNex campaign, J. Geophys. Res.-Atmos., 119, 1883-1902, https://doi.org/10.1002/2013JD020765, 2014.

Schwarz, J. P., Gao, R. S., Fahey, D. W., Thomson, D. S., Watts, L. A., Wilson, J. C., Reeves, J. M., Darbeheshti, M., Baumgardner, D. G., Kok, G. L., Chung, S. H., Schulz, M., Hendricks, J., Lauer, A., Kärcher, B., Slowik, J. G., Rosenlof, K. H., Thompson, T. L., Langford, A. O., Loewenstein, M., and Aikin, K. C.: Single-particle measurements of midlatitude black carbon and light-scattering aerosols from the boundary layer to the lower stratosphere, J. Geophys. Res., 111, D16207, https://doi.org/10.1029/2006JD007076, 2006.

Seinfeld, J. H. and Pandis, S. N.: Atmospheric Chemistry and Physics: From Air Pollution to Climate Change, John Wiley and sons, 2006.

Stelson, A. and Seinfeld, J. H.: Relative humidity and temperature dependence of the ammonium nitrate dissociation constant, Atmos. Environ., 16, 983-992, https://doi.org/10.1016/00046981(82)90184-6, 1982.

Terrenoire, E., Bessagnet, B., Rouïl, L., Tognet, F., Pirovano, G., Létinois, L., Beauchamp, M., Colette, A., Thunis, P., Amann, M., and Menut, L.: High-resolution air quality simulation over Europe with the chemistry transport model CHIMERE, Geosci. Model Dev., 8, 21-42, https://doi.org/10.5194/gmd-8-21-2015, 2015.

Thornton, J. A., Kercher, J. P., Riedel, T. P., Wagner, N. L., Cozic, J., Holloway, J. S., Dubé, W. P., Wolfe, G. M., Quinn, P. K., Middlebrook, A. M., Alexander, B., and Brown, S. S.: A large atomic chlorine source inferred from midcontinental reactive nitrogen chemistry, Nature, 464, 271-274, https://doi.org/10.1038/nature08905, 2010. 
Trousdell, J. F., Conley, S. A., Post, A., and Faloona, I. C.: Observing entrainment mixing, photochemical ozone production, and regional methane emissions by aircraft using a simple mixed-layer framework, Atmos. Chem. Phys., 16, 15433-15450, https://doi.org/10.5194/acp-16-15433-2016, 2016.

Vilà-Guerau De Arellano, J., van Heerwaarden, C. C., van Stratum, B. J. H., and van den Dries, K.: Atmospheric Boundary Layer, Integrating Air Chemistry and Land Interactions, Cambridge University Press, New York, 2015.

von Bobrutzki, K., Braban, C. F., Famulari, D., Jones, S. K., Blackall, T., Smith, T. E. L., Blom, M., Coe, H., Gallagher, M., Ghalaieny, M., McGillen, M. R., Percival, C. J., Whitehead, J. D., Ellis, R., Murphy, J., Mohacsi, A., Pogany, A., Junninen, H., Rantanen, S., Sutton, M. A., and Nemitz, E.: Field inter-comparison of eleven atmospheric ammonia measurement techniques, Atmos. Meas. Tech., 3, 91-112, https://doi.org/10.5194/amt-3-91-2010, 2010.

Wagner, N. L., Riedel, T. P., Young, C. J., Bahreini, R., Brock, C. A., Dubé, W. P., Kim, S., Middlebrook, A. M., Öztürk, F., Roberts, J. M., Russo, R., Sive, B., Swarthout, R., Thornton, J. A., VandenBoer, T. C., Zhou, Y., and Brown, S. S.: $\mathrm{N}_{2} \mathrm{O}_{5}$ uptake coefficients and nocturnal $\mathrm{NO}_{2}$ removal rates determined from ambient wintertime measurements, J. Geophys. Res.-Atmos., 118, 9331-9350, https://doi.org/10.1002/jgrd.50653, 2013.

Walker, J. M., Philip, S., Martin, R. V., and Seinfeld, J. H.: Simulation of nitrate, sulfate, and ammonium aerosols over the United States, Atmos. Chem. Phys., 12, 11213-11227, https://doi.org/10.5194/acp-12-11213-2012, 2012.

Wang, X., Zhang, Y., Chen, H., Yang, X., Chen, J., and Geng, F.: Particulate Nitrate Formation in a Highly Polluted Urban Area: A Case Study by Single-Particle Mass Spectrometry in Shanghai, Environ. Sci. Technol., 43, 3061-3066, https://doi.org/10.1021/es8020155, 2009.

Watson, J. G. and Chow, J. C.: A wintertime $\mathrm{PM}_{2.5}$ episode at the Fresno, CA, supersite, Atmos. Environ., 36, 465-475, https://doi.org/10.1016/S1352-2310(01)00309-0, 2002.
Whiteman, C. D., Hoch, S. W., Horel, J. D., and Charland, A.: Relationship between particulate air pollution and meteorological variables in Utah's Salt Lake Valley, Atmos. Environ., 94, 742753, https://doi.org/10.1016/j.atmosenv.2014.06.012, 2014.

Wild, R. J., Edwards, P. M., Bates, T. S., Cohen, R. C., de Gouw, J. A., Dubé, W. P., Gilman, J. B., Holloway, J., Kercher, J., Koss, A. R., Lee, L., Lerner, B. M., McLaren, R., Quinn, P. K., Roberts, J. M., Stutz, J., Thornton, J. A., Veres, P. R., Warneke, C., Williams, E., Young, C. J., Yuan, B., Zarzana, K. J., and Brown, S. S.: Reactive nitrogen partitioning and its relationship to winter ozone events in Utah, Atmos. Chem. Phys., 16, 573 583, https://doi.org/10.5194/acp-16-573-2016, 2016.

Young, D. E., Kim, H., Parworth, C., Zhou, S., Zhang, X., Cappa, C. D., Seco, R., Kim, S., and Zhang, Q.: Influences of emission sources and meteorology on aerosol chemistry in a polluted urban environment: results from DISCOVER-AQ California, Atmos. Chem. Phys., 16, 5427-5451, https://doi.org/10.5194/acp16-5427-2016, 2016.

Zhang, X., Massoli, P., Quinn, P. K., Bates, T. S., and Cappa, C. D.: Hygroscopic growth of submicron and supermicron aerosols in the marine boundary layer, J. Geophys. Res.-Atmos., 119, 83848399, https://doi.org/10.1002/2013JD021213, 2014.

Zhang, X., Kim, H., Parworth, C. L., Young, D. E., Zhang, Q., Metcalf, A. R., and Cappa, C. D.: Optical Properties of Wintertime Aerosols from Residential Wood Burning in Fresno, CA: Results from DISCOVER-AQ 2013, Environ. Sci. Technol., 50, 16811690, https://doi.org/10.1021/acs.est.5b04134, 2016. 